\title{
Caspase-9: A Multimodal Therapeutic Target With Diverse Cellular Expression in Human Disease
}

Maria I. Avrutsky ${ }^{1 *}$ and Carol M. Troy ${ }^{1,2,3 *}$

${ }^{1}$ Department of Pathology and Cell Biology, Vagelos College of Physicians and Surgeons, Columbia University, New York, NY, United States, ${ }^{2}$ Department of Neurology, Vagelos College of Physicians and Surgeons, Columbia University, New York, NY, United States, ${ }^{3}$ The Taub Institute for Research on Alzheimer's Disease and the Aging Brain, Vagelos College of Physicians and Surgeons, Columbia University, New York, NY, United States

OPEN ACCESS

Edited by:

Chiranjib Chakraborty, Adamas University, India

Reviewed by: Kakoli Bose

Tata Memorial Hospital, India Banyuhay Serrano, Harvard Medical School, United States

*Correspondence:

Maria I. Avrutsky mia2120@caa.columbia.edu Carol M. Troy cmt2@cumc.columbia.edu

Specialty section: This article was submitted to Experimental Pharmacology and Drug Discovery, a section of the journa Frontiers in Pharmacology

Received: 27 April 2021 Accepted: 28 June 2021 Published: 09 July 2021

Citation: Avrutsky MI and Troy CM (2021) Caspase-9: A Multimodal Therapeutic Target With Diverse Cellular Expression in Human Disease.

Front. Pharmacol. 12:701301. doi: 10.3389/fphar.2021.701301
Caspase-9, a cysteine-aspartic protease known for its role as an initiator of intrinsic apoptosis, regulates physiological cell death and pathological tissue degeneration. Its nonapoptotic functions, including regulation of cellular differentiation/maturation, innate immunity, mitochondrial homeostasis, and autophagy, reveal a multimodal landscape of caspase- 9 functions in health and disease. Recent work has demonstrated that caspase- 9 can drive neurovascular injury through nonapoptotic endothelial cell dysfunction. CASP9 polymorphisms have been linked with various cancers, neurological disorders, autoimmune pathologies and lumbar disc disease. Clinical reports suggest alterations in caspase- 9 expression, activity or function may be associated with acute and chronic neurodegeneration, retinal neuropathy, slow-channel myasthenic syndrome, lumbar disc disease, cardiomyopathies, atherosclerosis and autoimmune disease. Healthy tissues maintain caspase- 9 activity at low basal levels, rendering supraphysiological caspase- 9 activation a tractable target for therapeutic interventions. Strategies for selective inhibition of caspase-9 include dominant negative caspase-9 mutants and pharmacological inhibitors derived from the XIAP protein, whose Bir3 domain is an endogenous highly selective caspase- 9 inhibitor. However, the mechanistic implications of caspase- 9 expression and activation remain indeterminate in many pathologies. By assembling clinical reports of caspase-9 genetics, signaling and cellular localization in human tissues, this review identifies gaps between experimental and clinical studies on caspase-9, and presents opportunities for further investigations to examine the consequences of caspase activity in human disease.

Keywords: caspase-9, apoptosis, neurodegeneration, retina, cardiomyopathy, innate immunity, cancer, cardiovascular disease

\section{INTRODUCTION}

Caspases are a conserved family of cysteine-aspartic proteases that mediate programmed cell death and inflammation. Cells express caspases as inactive zymogens, which activate rapidly in response to cellular signals. Initiator caspases (caspase-1, -2, -8, -9, -10) activate through dimerization upon binding to an activating platform. Once active, initiator caspases activate downstream effector caspases (such as caspase- $3,-6$, and -7 ) by proteolytic cleavage, which can in turn activate additional initiator caspases (McComb et al., 2019). Consequently, an initiator caspase can trigger a signaling 
cascade that activates multiple initiator and effector caspases. Caspase cleavage does not degrade substrate proteins, but rather introduces loss-of-function or gain-of-function signaling events (Bratton and Salvesen, 2010). Effector caspases have hundreds of identified cleavage substrates, and the cellular consequence of caspase activity is often a cooperative function of multiple proteolytic events (Julien and Wells, 2017), enabling these proteases to play diverse roles in physiological and pathological contexts.

Here, we focus our attention on clinical reports of altered caspase- 9 activity or function in human tissues to provide an overview of the clinical correlates between caspase- 9 and disease pathologies. Due to the lack of clinicals approaches for modulating caspase- 9 activity, these studies are by necessity correlative. However, functional human genetics and animal models provide mechanistic insight into the role of caspase- 9 in disease progression. Our goal is to assemble a framework linking in vitro and in vivo experimental studies with clinical literature on caspase-9 involvement in human disease.

\section{CASPASE-9 ACTIVITY AND REGULATION}

Caspase-9 activation occurs in the apoptosome, a heptameric structure comprised of Apaf-1 (Apoptotic protease activating factor 1) and cytochrome $c$, which forms in response to permeabilization of the mitochondrial outer membrane and release of cytochrome $\mathrm{c}$ into the cytosol (Figure 1) (Bratton and Salvesen, 2010). Binding to Apaf-1 activates full-length procaspase-9 through proximity-induced dimerization and conformational change, which brings its catalytic subunits together to form an active site. An alternative pathway of caspase- 9 activation that does not require Apaf-1 has been reported in HeLa cells and in hippocampal neural stem cells upon induction of autophagy by insulin deprivation (An et al., 2019). In both activation modalities, active caspase- 9 autocleaves to generate a cleaved caspase- 9 (cl-caspase-9) neoepitope at D315. Caspase- 9 can also be cleaved by caspase-3, generating an alternate neoepitope at D330. Both D315 cl-caspase-9 and D330 cl-caspase9 are fully active proteases. However, the two neopitopes are differentially susceptible to regulation by XIAP (X-linked Inhibitor of Apoptosis Protein), since the Bir3 (Baculoviral Inhibitory Repeat 3) domain of XIAP selectively inhibits caspase-9 at the D315 epitope (Denault et al., 2007). Neoepitope-specific antibodies for the D315 and D330 cleavage sites thus provide insight into caspase signaling pathways, since the D330 neoepitope indicates prevalent co-current caspase- 3 activity.

Caspase- 9 can activate effector caspases, or act directly on other cellular substrates, by cleaving target proteins after an aspartic acid residue surrounded by a caspase- 9 cleavage motif. The most well-characterized consequence of caspase-9 activation is cleavage of downstream effector caspases to induce apoptotic cell death. During apoptosis, caspase- 9 helps dismantle intermediate filaments via direct cleavage of vimentin (Nakanishi et al., 2001), and inhibits polycomb protein function by cleaving Ring Finger Protein 2 (RNF2) (Wong et al., 2007). Meanwhile, caspase- 9 cleavage of caspase- 6 contributes to axonal degeneration in ischemic stroke (Akpan et al., 2011). Additional cellular substrates of caspase-9 include Major Vault Protein (MVP), which can be inactivated by caspase- 9 cleavage in apoptotic epithelial cells (Grossi et al., 2020). Interestingly, MVP cleavage is observed in primary human keratinocytes and fibroblasts, but not in THP-1 cells (monocytic cell line), highlighting the importance of considering cell-specific contexts when investigating caspase activity. In addition to promoting apoptotic cell death, caspase- 9 contributes to necroptosis, an immune-system mediated form of cell death that serves as a backup mechanism to extrinsic cell death. Caspase- 9 interacts with necrosis mediator RIPK3 (receptor-interacting serine/ threonine-protein kinase 3), and in an in vivo model of pancreatic necroptosis, knockout of caspase- 9 from pancreatic acinar cells results in decreased severity of cerulein-induced acute pancreatitis (Molnár et al., 2021).

Caspase-9 also has multiple physiological nondeath functions. Caspase-9-mediated activation of effector caspases promotes myocyte differentiation and proliferation (Murray et al., 2008), hematopoietic development ( $\mathrm{Lu}$ et al., 2014), and immune response to viral infection (Rongvaux et al., 2014). Meanwhile, caspase-9-mediated cleavage of semaphorin7a is required for proper axonal projection during olfactory development (Ohsawa et al., 2010). Intriguingly, both caspase-9 and semaphorin7a (Morote-Garcia et al., 2012; Hu et al., 2018) mediate endothelial hypoxia and inflammatory injury responses. Caspase- 9 plays both apoptotic and nonapoptotic roles in ischemic neurovascular injury; ischemic neurons die by caspase- 9 mediated apoptosis, while nonlethal activation of caspase- 9 in endothelial cells contributes to capillary nonperfusion and vascular edema (Avrutsky et al., 2020). However, it is not known if caspase- 9 and semaphorin7a act through shared or separate pathways in endothelial cells. Nonapoptotic caspase-9 signaling is also essential for postnatal motor circuit reorganization, and mice with deficient caspase- 9 activation exhibit corticospinal circuit defects and skilled movement deficits ( $\mathrm{Gu}$ et al., 2017). Corticospinal axon elimination depends on nonapoptotic caspase- 9 activity, and this function likely does not require effector caspases-3, -6 or -7 (Gu et al., 2020). Caspase-9 activity is also essential for mitochondrial homeostasis; pharmacological or genetic ablation of caspase- 9 results in depolarization of mitochondrial membrane potential, reduced reactive oxygen species production, aberrant accumulation of mitochondrial fusion-fission proteins and reduced autophagy flux (An et al., 2019). This function is dependent on caspase- 9 cleavage activity, but it is not clear if effector caspases are relevant substrates for this pathway. Meanwhile, non-catalytic caspase-9 regulates endosomal sorting and lysosomal biogenesis by facilitating retrograde transport of IGFR2 from endosomes to the trans-Golgi network (Han et al., 2020b).

Regulatory pathways enable fine-tuned cellular control of caspase- 9 activity. Caspase-9b, an endogenous alternativelyspliced short isoform of caspase-9, lacks the large catalytic subunit and inhibits apoptosis by competing with full-length caspase-9 for binding to the apoptosome (Srinivasula et al., 1999). Additionally, caspase-9b can activate the NF- $\kappa \mathrm{B}$ pro-survival pathway through interaction with cIAP1 (cellular Inhibitor of Apoptosis 1) (Srinivasula et al., 1999; Vu et al., 2016). Caspase-9b 


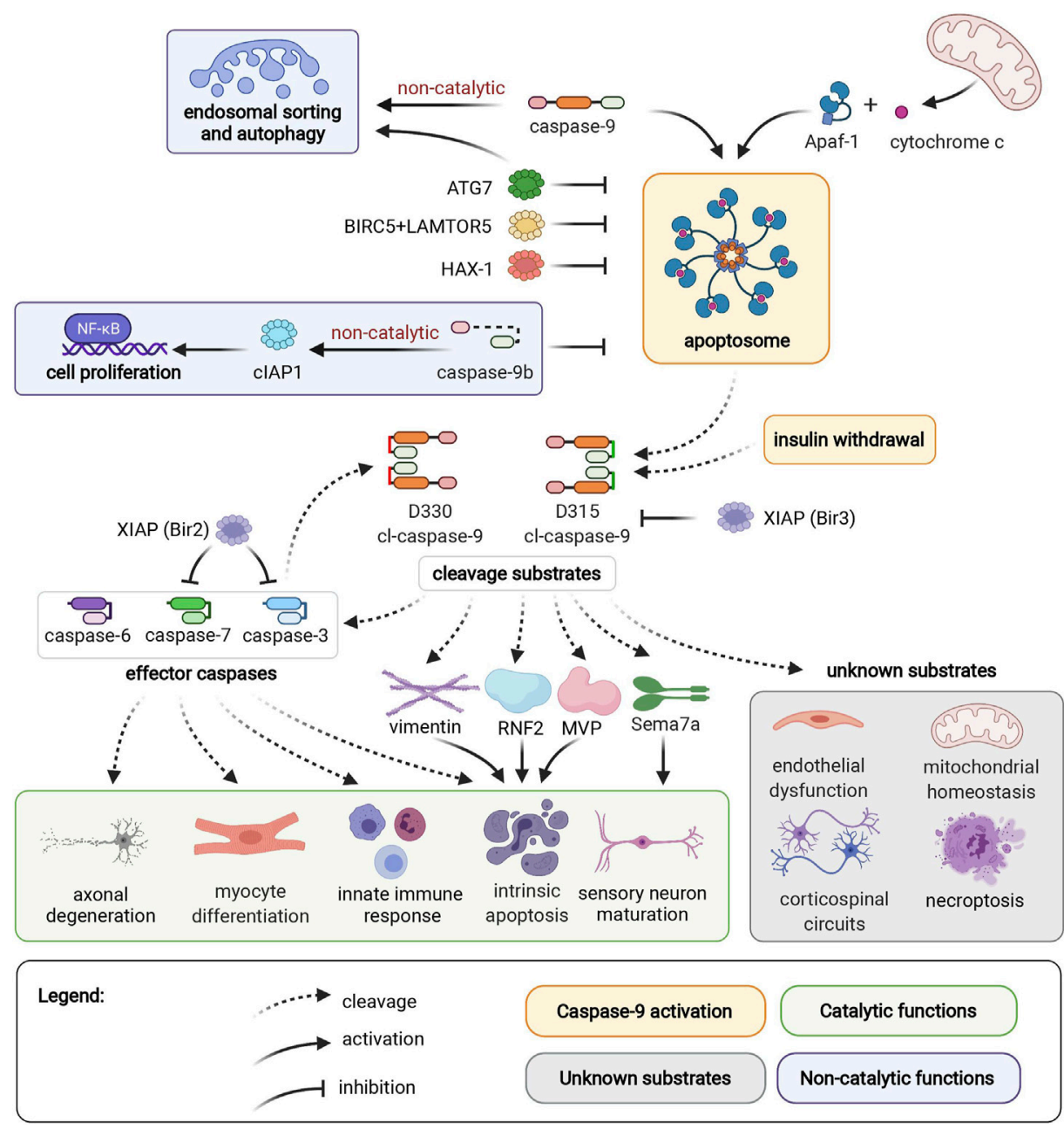

FIGURE 1 | Caspase-9 activation, cleavage substrates, and cellular functions. Caspase- 9 can be activated by binding to Apaf- 1 in the apoptosome, or by an independent mechanism induced by insulin withdrawal. Endosomal sorting and autophagy are regulated by caspase-9 through a non-catalytic mechanism. ATG7, BIRC5/LAMTOR5 complex, and HAX-1 inhibit caspase- 9 activation. Non-catalytic caspase-9b inhibits caspase-9 activation, and promotes cell proliferation through the NF-kB pathway. D315 and D330 neoepitopes of caspase-9 are generated by autocleavage, or caspase-3 cleavage, respectively. Caspase- 9 substrates include caspases -3, -6, -7, vimentin, RNF2, MVP, and Sema7a. These cleavage events mediate axonal degeneration, myocyte differentiation, innate immune response, intrinsic apoptosis, and sensory neuron maturation. Caspase-9 mediates endothelial dysfunction, corticospinal circuits, mitochondrial homeostasis, and necroptosis through unidentified mediator substrates. The Bir3 domain of XIAP inhibits D315 cl-caspase-9, while the Bir2 domain of XIAP inhibits effector caspases-3 and -7. Apoptotic protease activating factor 1 (Apaf1); Autophagy Related 7 (ATG7); survivin (BIRC5); Late Endosomal/Lysosomal Adaptor, MAPK And MTOR Activator 5 (LAMTOR5); HCLS1-Associated Protein X-1 (HAX-1); Ring Finger Protein 2 (RNF2); Major Vault Protein (MVP), semaphorin 7a (Sema7a); X-linked Inhibitor of Apoptosis Protein (XIAP).

expression is upregulated in several cancers, potentially providing an apoptosis-evasion strategy for tumors with high levels of caspase-9 expression (Shultz and Chalfant, 2011). Inhibitory phosphorylation (Allan and Clarke, 2009; Serrano et al., 2017) and nitrosylation (Török et al., 2002; Zhang et al., 2016) sites regulate caspase- 9 activation by interfering with caspase- 9 binding to the apoptosome, or by preventing proteolytic processing of caspase- 9 by other caspases (McDonnell et al., 2008). Additionally, antiapoptotic proteins such as XIAP (Denault et al., 2007; Han et al., 2014), survivin/BIRC5 (Baculovirus IAP Repeat Containing 5) complexed with LAMTOR5 (Late Endosomal/Lysosomal Adaptor MAPK and MTOR Activator 5) (Marusawa et al., 2003), HAX-1
(HCLS1-Associated Protein X-1) (Han et al., 2006; Yan et al., 2015), and ATG7 (Autophagy Related 7) (Han et al., 2014) downregulate the apoptotic potential of caspase-9. This milieu of caspase- 9 regulation enables a diversity of cell- and contextspecific consequences of caspase- 9 activation.

\section{EXPERIMENTAL AND CLINICAL STRATEGIES FOR MODULATING CASPASE- 9}

Genetic approaches enable specific inhibition of caspase-9 activity, either through deletion of the CASP9 gene, or via ectopic 
expression of catalytically inactive caspase- 9 constructs, which function as dominant negative mutants (Lopez-Hernandez et al., 2004; Wang et al., 2011; Baechler et al., 2019). Alternatively, selective pharmacologic inhibition of caspase-9 can be achieved by leveraging cell permeant peptides to enable intracellular delivery of the Bir3 domain of XIAP (Akpan et al., 2011; Avrutsky et al., 2020). Inhibitors based on LEHD, a tetrapeptide caspase inhibitor, are also commonly used to inhibit caspase-9. However, such methods lack specificity due to the overlapping cleavage motifs of apoptotic caspases (McStay et al., 2008; Pereira and Song, 2008). Likewise, cleavage assays based on tetrapeptide substrates (such as DEVD or LEHD) indicate when caspases are active in a tissue sample, but cannot reliably differentiate between specific caspases. The lack of selectivity enabled by these tools results in ambiguous interpretation of data due to the frequent involvement of multiple caspases in converging signaling pathways. Since caspase-9 (and downstream effector caspases) can mediate both apoptotic and nonapoptotic cellular functions, readouts such as TUNEL staining or annexin A5 uptake are useful tools for determining when caspase activity is associated with cell death.

Selective induction of apoptosis via inducible caspase-9 has potential therapeutic utility as a safety-switch against overgrowth of cellular grafts. Rivo-cel (CaspaCIDe System, or inducible caspase-9) is a clinical-stage technology developed by Bellicum, which involves pre-transplant transfection of donor T-cells with a chemically inducible caspase- 9 gene that can be activated by a small molecule dimerization enhancer (Wu et al., 2014). The therapy entered several phase II trials for improving hematopoietic stem cell transplantation outcomes in the treatment of leukemias, lymphomas and inherited blood disorders by conferring prophylaxis against graft vs host disease. Inducible caspase-9 is also being explored as a potential fail-safe system to protect against the tumorigenic potential of stem cell therapies (Nishimura et al., 2019).

Clinical tools for inhibiting caspase- 9 activity are far more limited, as no selective caspase- 9 inhibitors have yet entered clinical development. Emricasan [IDN-6556], a small molecule irreversible pan-caspase inhibitor, entered clinical trials for treatment of non-alcoholic steatohepatitis (NASH), portal hypertension, and liver failure/cirrhosis. The treatment was generally well tolerated, supporting the clinical feasibility of targeting caspases as a therapeutic strategy, but failed to meet primary efficacy endpoints (Harrison et al., 2020). The lack of clinical tools for inhibiting caspase- 9 activity or expression presents a challenge for interpreting the mechanistic significance of caspase9 alterations in human disease pathologies. Consequently, our current understanding of the pathologic implications of caspase9 relies on correlational studies from patient data and, when available, interventional studies in animal models of disease.

\section{GENETICS OF CASPASE-9 IN HUMAN DISEASE}

Table 1 highlights caspase-9 promoter and gene sequence variants that have been associated with differential health outcomes. Studies have characterized several mutations in the caspase- 9 adaptor domain and large catalytic domain, which result in impaired apoptotic potential (Figure 2). Loss-offunction mutations in CASP9 (as well as in apoptosis-related genes CASP3 and APAF1) have been identified in cases of neural tube defects (NTDs) (Liu et al., 2018; Spellicy et al., 2018; Zhou et al., 2018). Liu et al. (Liu et al., 2018) characterized functional consequences of three variants (G66A, R191G, Y251C) specific to patients with NTDs. All three variants showed impaired apoptosis in 293T cells cultured under low folate conditions, suggesting that folate insufficiency (a known risk factor for NTDs) may be an environmental factor in cases carrying these mutations. The Y251C mutation occurs in a conserved region of the large catalytic subunit, and likely disrupts caspase- 9 protein stability; 293T and NE-4C cells express Y251C caspase-9 at 0.35-0.5-fold lower levels compared to WT constructs (Liu et al., 2018; Zhou et al., 2018). The H237P variant (rs146054764), occurring in trans with a G309* frameshift mutation in two sibling fetuses diagnosed with craniorachischisis, results in complete absence of detectable caspase- 9 protein expression, and substantially downregulated apoptosis in fetal fibroblasts, suggesting that this amino residue is critical for caspase-9 protein stability (Spellicy et al., 2018). Meanwhile, the R180C and R191G variants express at normal levels in transfected $293 \mathrm{~T}$ cells, but fail to effectively induce apoptosis due to inability to interact with Apaf-1 (Liu et al., 2018; Zhou et al., 2018). Protein prediction analysis indicates that these substitutions may have a damaging consequence on caspase- 9 protein structure.

Caspase- 9 variants associated with cases of NTDs replicate the phenotype of CASP9 deletion in murine studies, which results in embryonic lethality due to severe brain malformations and hindbrain neural tube defects (Kuida et al., 1998). Knockout animals exhibit disorganization of cerebral structures, reduced neuronal apoptosis, accumulation of necrotic tissues in the brain, and frequent intracerebral hemorrhages (Hakem et al., 1998), reflecting the importance of caspase- 9 in neural development.

Caspase- 9 coding variants have also been associated with immune system pathologies. Localized deletion of murine caspase-9 from hematopoietic progenitors impairs leukocyte proliferation and differentiation ( $\mathrm{Lu}$ et al., 2014), and dysregulates cell intrinsic immune response (Rongvaux et al., 2014). Clemente et al. (Clemente et al., 2015) describes how the H237P (rs146054764) variant may predispose affected individuals to immunodeficiency and lymphoproliferation. Functional characterization of the $\mathrm{H} 237 \mathrm{P}$ variant in peripheral blood mononuclear cells (PBMCs) from the affected patients, and in PBMCs from healthy donors transfected with a H237P construct, reveals defective proliferative and apoptotic responses. In transfected $293 \mathrm{~T}$ cells, H237P caspase-9 fails to associate with Apaf-1, and produces a dominant negative effect on the activation of WT caspase-9. Ex vivo analysis of patient lymphocytes and in vitro transfection studies show that deficits in caspase- 9 activity cause impaired lymphocyte apoptosis and activation via downregulation of BAFFR (B-cell-activating factor belonging to the TNF family (BAFF) receptor) in B cells and ICOS (inducible T-cell costimulator) in $\mathrm{T}$ cells. 
TABLE 1 | Caspase-9 polymorphisms linked to human disease.

\begin{tabular}{|c|c|c|c|c|}
\hline Ensembl & Polymorphism/gnomAD & CASP9 tissue eQTL & $\begin{array}{l}\text { Association (affect allele } \\
\text { risk } \uparrow \text { or } \downarrow \text { ) }\end{array}$ & Ref. \\
\hline rs4645978 & Promoter 1-15852034-C-T & $\begin{array}{l}\text { Brain - Spinal cord } \uparrow \\
\text { Mammary tissue } \uparrow \\
\text { Whole blood } \uparrow \\
\text { Pancreas } \uparrow \\
\text { Colon } \uparrow \\
\text { Stomach } \uparrow\end{array}$ & $\begin{array}{l}\text { Lumbar disc disease } \downarrow \\
\text { Breast cancer } \downarrow \\
\text { Acute myeloid leukemia } \downarrow \\
\text { Pancreatic cancer } \downarrow \\
\text { Colorectal cancer } \uparrow \\
\text { Gastric cancer } \uparrow\end{array}$ & $\begin{array}{l}\text { Guo et al. (2011b); Zhang et al. } \\
\text { (2013a); Mu et al. (2013) } \\
\text { Theodoropoulos et al. (2012) } \\
\text { Cingeetham et al. (2014) } \\
\text { Theodoropoulos et al. (2010) } \\
\text { Theodoropoulos et al. (2011) } \\
\text { Liamarkopoulos et al. (2011) }\end{array}$ \\
\hline rs4645981 & Promoter 1-15851483-G-A & N/A & $\begin{array}{l}\text { Breast cancer } \uparrow \\
\text { Lung Cancer } \uparrow \\
\text { Hepatocellular carcinoma } \uparrow \\
\text { Acute myeloid leukemia } \uparrow \\
\text { General cancer risk } \uparrow\end{array}$ & $\begin{array}{l}\text { Lee et al. (2010) } \\
\text { Yoo et al. (2009); Lee et al. (2010); } \\
\text { Xu et al. (2012) } \\
\text { Zhang et al. (2017) } \\
\text { Cingeetham et al. (2014) } \\
\text { Zhang et al. (2013b) }\end{array}$ \\
\hline rs4661636 & Intron 1-15823061-C-T & $\begin{array}{l}\text { Whole blood } \downarrow \\
\text { Esophagus } \downarrow\end{array}$ & $\begin{array}{l}\text { Non-Hodgkin's lymphoma } \downarrow \\
\text { Esophageal adenocarcinoma } \uparrow\end{array}$ & $\begin{array}{l}\text { Lan et al. (2009) } \\
\text { Liu et al. (2010) }\end{array}$ \\
\hline rs2020902 & Intron 1-15834360-A-G & $\begin{array}{l}\text { Blood } \downarrow \\
\text { Kidney } \uparrow\end{array}$ & $\begin{array}{l}\text { Non-Hodgkin's lymphoma } \downarrow \\
\text { New-onset diabetes after renal } \\
\text { transplant } \uparrow\end{array}$ & $\begin{array}{l}\text { Kelly et al. (2010) } \\
\text { McCaughan et al. (2014) }\end{array}$ \\
\hline rs2042370 & Intron 1-15841742-G-A & Whole blood $\uparrow$ & Non-Hodgkin's lymphoma $\downarrow$ & Kelly et al. (2010) \\
\hline rs6685648 & Intron 1-15825195-T-C & $\begin{array}{l}\text { Whole blood } \uparrow \\
\text { Lung } \uparrow\end{array}$ & $\begin{array}{l}\text { Non-Hodgkin's lymphoma } \uparrow \\
\text { Lung cancer } \uparrow\end{array}$ & $\begin{array}{l}\text { Kelly et al. (2010) } \\
\text { Lin et al. (2012) }\end{array}$ \\
\hline rs372045782 & $\begin{array}{l}\text { Coding (R173C) } \\
\text { Coding (R180C); loss of function } \\
\text { Coding (R191G); loss of function }\end{array}$ & $\mathrm{N} / \mathrm{A}$ & $\begin{array}{l}\text { Neural tube defects } \uparrow \\
\text { Neural tube defects } \uparrow \\
\text { Neural tube defects } \uparrow\end{array}$ & $\begin{array}{l}\text { Liu et al. (2018); Zhou et al. (2018) } \\
\text { Zhou et al. (2018) } \\
\text { Liu et al. (2018); Zhou et al. (2018) }\end{array}$ \\
\hline rs1052576 & Coding (Q221R) 1-15832543-T-C & Brain - Spinal cord $\uparrow$ Brain $\uparrow$ & $\begin{array}{l}\text { Lumbar disc disease } \uparrow \\
\text { Non-Hodgkin's lymphoma } \uparrow \\
\text { Multiple myeloma } \uparrow \\
\text { General cancer risk } \uparrow \\
\text { Glioma } \uparrow \\
\text { Multiple sclerosis } \uparrow\end{array}$ & $\begin{array}{l}\text { Sun et al. (2011) } \\
\text { Lan et al. (2007) } \\
\text { Hosgood et al. (2008) } \\
\text { Zhang et al. (2013b) } \\
\text { Ozdogan et al. (2017) } \\
\text { Andreoli et al. (2009) }\end{array}$ \\
\hline rs146054764 & $\begin{array}{l}\text { Coding (H237P); dominant } \\
\text { negative 1-15832495-T-G }\end{array}$ & N/A & $\begin{array}{l}\text { Immunodeficiency/lymphoproliferation } \uparrow \\
\text { Neural tube defects } \uparrow\end{array}$ & $\begin{array}{l}\text { Clemente et al. (2015) } \\
\text { Spellicy et al. (2018) }\end{array}$ \\
\hline rs552167727 & $\begin{array}{l}\text { Coding (Y251C); loss of function } \\
\text { Frameshift (G309*) }\end{array}$ & $\mathrm{N} / \mathrm{A}$ & $\begin{array}{l}\text { Neural tube defects } \uparrow \\
\text { Neural tube defects } \uparrow\end{array}$ & $\begin{array}{l}\text { Liu et al. (2018); Zhou et al. (2018) } \\
\text { Spellicy et al. (2018) }\end{array}$ \\
\hline
\end{tabular}

List of disease associations reported for caspase-9 polymorphisms, and associated eQTLs (GTex Portal) indicating whether the SNPs are associated with increased or decreased levels of caspase-9 expression. Reference sequence IDs from dbSNP. 


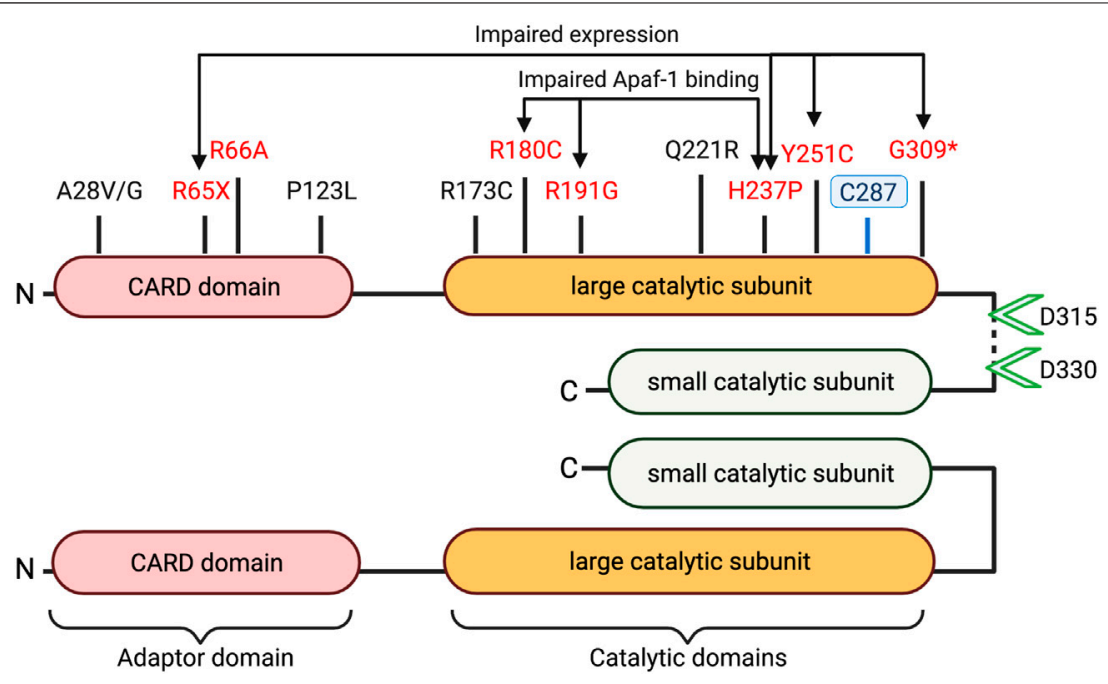

FIGURE 2 | Caspase-9 domains and coding sequence variants. Schematic structure of dimerized active caspase-9 domains is depicted with proteolytic cleavage sites (green arrowheads) and catalytic site cysteine at C287 indicated. Disease associated variants marked in black (uncharacterized mutations) or red (loss of function). $\left(^{\star}=\right.$ Frameshift, $\mathrm{X}=$ stop-gain).

Several other CASP9 polymorphisms have also been associated with autoimmune and hematopoietic pathologies. The coding variant $\mathrm{A} 28 \mathrm{~V} / \mathrm{G}$ (rs1052571) is associated with lower risk of severe ulcerative colitis (Guo et al., 2011a), and the Q221R (rs1052576) mutation has been identified as a susceptibility locus for multiple sclerosis in Italy (Andreoli et al., 2009). Both loci are associated with significantly increased CASP9 expression across multiple tissues by eQTL (expression Quantitative Trait Loci) analysis on the GTex Portal. While it has been speculated that the Q221R variant may cause a conformational change modifying the affinity of caspase- 9 to Apaf-1 (Xu et al., 2012), the functional consequences of the $\mathrm{A} 28 \mathrm{~V} / \mathrm{G}$ and the Q221R mutations have not been experimentally shown to alter caspase-9 activity or function. Comparison of genotyped primary human lymphocytes found no differences in benzo [a]pyrene-7,8-9,10-diol epoxide (BPDE)induced apoptosis in cells carrying the Q221R mutation compared to WT caspase-9 (Hu et al., 2008). Thus, functional validation of the $\mathrm{A} 28 \mathrm{~V} / \mathrm{G}$ and $\mathrm{Q} 221 \mathrm{R}$ mutations will be necessary to establish if these variants alter caspase-9 activity, its recruitment to the apoptosome, or its expression in a way that contributes to the associated autoimmune phenotypes.

Even greater challenges relate to understanding noncoding CASP9 polymorphisms associated with hematopoietic malignancies (Hosgood et al., 2008; Lan et al., 2009; Kelly et al., 2010; Cingeetham et al., 2014), new-onset diabetes after renal transplant (McCaughan et al., 2014), and treatment efficacy for Crohn's disease (Hlavaty et al., 2005; Ferreira et al., 2010; Cravo et al., 2014). Biochemical analysis of patient samples can help identify if these noncoding variants are correlated with alterations in caspase- 9 activity or expression in disease-relevant tissues.

\section{Genetics of Caspase-9 in Human Cancer}

Evasion of apoptosis is a hallmark of human cancers, and the role of caspases in carcinogenesis has been studied extensively
(Olsson and Zhivotovsky, 2011; Shalini et al., 2015), due to their key functions in regulating cellular differentiation, proliferation, and apoptosis. Caspase-9 can suppress tumor growth by triggering intrinsic apoptosis in response to cellular damage such as genomic instability, oxidative stress, and aberrant proliferation. However, while some tumors inhibit caspase- 9 as an apoptosis-evasion strategy (Chee et al., 2013), cellular survival is regulated by interactions of multiple apoptotic proteins. Pharmacological inhibition of caspase- 9 can help sensitize cancer cells to chemotherapy by promoting caspase-8-dependent apoptosis (Tamaki et al., 2014). Tumor cells can also hijack caspase- 9 signaling to suppress radiation-induced immunity; deletion of caspase- 9 or pharmacological pan-caspase inhibition with Emricasan can sensitize cancer cells to radiation therapy by rescuing type I interferon production in irradiated cells (Han et al., 2020a). Additionally, apoptosis not only induces cell death, but also triggers cellular proliferation in surrounding tissues, which can promote tumor growth (Fogarty and Bergmann, 2017).

Mutation or loss of CASP9 heterozygosity is rarely observed in human cancers (Olsson and Zhivotovsky, 2011; Ronellenfitsch et al., 2018). The strongest functional genetic association between caspase- 9 and cancer is a stop-gain mutation at R65, which results in a catalytically inactive short isoform of caspase-9, and may cause increased susceptibility to development of anaplastic astrocytomas consistent with Li-Fraumeni-like syndrome (Ronellenfitsch et al., 2018). A heterozygous germline R65X mutation was identified in two related patients and two unaffected family members. Analysis of the patients' anaplastic astrocytomas revealed additional tumor-specific mutations in IDH1 and TP53, and absence of caspase-9 immunoreactivity in both tumor and healthy brain tissues. An additional CASP9 stop-gain mutation was identified in a pediatric glioma patient, suggesting that caspase- 9 loss-of-function may contribute to the pathogenesis of some pediatric brain cancers (Muskens et al., 
TABLE 2 | Studies reporting increased level of caspase-9 in neurodegenerative pathologies.

\begin{tabular}{|c|c|c|c|c|c|c|}
\hline Disease (n) & Controls (n) & Casp9 Measured & Detection Method & Tissue Examined & $\begin{array}{c}\text { Pathological Casp9 } \\
\text { Localization }\end{array}$ & Ref. \\
\hline MSA (10) & Normal (8) & D330 cl-casp9 & $\mathrm{IHC}$ & $\begin{array}{l}\text { Basal ganglia, cerebellum, } \\
\text { midbrain, pons, medulla } \\
\text { (postmortem) }\end{array}$ & $\begin{array}{l}\text { Oligodendrocytes, } \\
\text { neurons, glia }\end{array}$ & $\begin{array}{l}\text { Kawamoto et al. } \\
(2016)\end{array}$ \\
\hline ALS (5-8) & $\begin{array}{l}\text { Cerebrovascular disease } \\
\text { w/o spinal cord } \\
\text { pathology (3-5) }\end{array}$ & $\begin{array}{l}\text { Unspecified cl-casp9 } \\
\text { Caspase activity }\end{array}$ & $\begin{array}{l}\mathrm{IHC} \\
\text { LEHD-cleavage }\end{array}$ & $\begin{array}{l}\text { Spinal cord, anterior horn } \\
\text { (postmortem) }\end{array}$ & Motor neurons & $\begin{array}{l}\text { Inoue et al. } \\
\text { (2003) }\end{array}$ \\
\hline ALS (30) & Tension-type headache (30) & Total casp9 & ELISA & Serum & -- & Ilzecka (2012) \\
\hline $\mathrm{AD}(7)$ & Normal (7) & D315 cl-casp9 & $\mathrm{IHC}$ & $\begin{array}{l}\text { Hippocampus, frontal cortex } \\
\text { (postmortem) }\end{array}$ & $\begin{array}{l}\text { Neurons, neurofibrillary } \\
\text { tangles }\end{array}$ & $\begin{array}{l}\text { Rohn et al. } \\
(2002)\end{array}$ \\
\hline $\begin{array}{l}\mathrm{AD}(50) \\
\mathrm{aMCl}(50)\end{array}$ & Normal (50) & Full-length casp9 & Western blot & Blood & Platelet rich plasma & Zhao et al. (2016) \\
\hline HD (19) & Normal (6) & D330 cl-casp9 & Western blot, IHC & Striatum (postmortem) & Neuropil, neurons & $\begin{array}{l}\text { Kiechle et al. } \\
\text { (2002) }\end{array}$ \\
\hline TBI (9) & Normal (5) & Unspecified cl-casp9 & ELISA & CSF & -- & $\begin{array}{l}\text { Darwish and } \\
\text { Amiridze (2010) }\end{array}$ \\
\hline $\begin{array}{l}\text { TBI- } \\
\text { severe (45) }\end{array}$ & Normal (25) & Total casp9 & ELISA & CSF & -- & $\begin{array}{l}\text { Jiang et al. } \\
(2020)\end{array}$ \\
\hline
\end{tabular}

MSA, Multiple system atrophy; ALS, Amyotrophic lateral sclerosis; AD, Alzheimer's disease; aMCI, amnesic mild cognitive impairment; HD, Huntington's disease; TBI, Traumatic brain injury.

2020).The Q221R mutation of caspase-9 has been associated with increased risk of multiple malignancies (Lan et al., 2007; Hosgood et al., 2008; Zhang et al., 2013b; Ozdogan et al., 2017), however as discussed previously, the functional consequence of this single nucleotide polymorphism (SNP) remains unclear.

Several intron and promoter region polymorphisms in CASP9 have been associated with incidence and progression of various cancers, including lung (Yoo et al., 2009; Lee et al., 2010; Lin et al., 2012; Xu et al., 2012), esophagus (Liu et al., 2010; Costa et al., 2019), liver (Zhang et al., 2017), breast (Theodoropoulos et al., 2012), and hemopoietic malignancies (Lan et al., 2007; Hosgood et al., 2008; Lan et al., 2009; Kelly et al., 2010; Cingeetham et al., 2014). However, eQTL analysis shows no concordance between tissue-specific effects of disease-associated SNPs on caspase-9 expression, and the directionality of associated disease risks (see Table 1). Furthermore, some variants have reported opposite risk effects for different cancers. The $T$ allele at the CASP9 promoter SNP rs4645978 has been associated with increased risks of colorectal (Theodoropoulos et al., 2011) and gastric (Liamarkopoulos et al., 2011) cancers, but decreased risks of breast cancer (Theodoropoulos et al., 2012), acute myeloid leukemia (Cingeetham et al., 2014), and pancreatic cancer (Theodoropoulos et al., 2010). Similarly, the $T$ allele of the intron polymorphism rs4661636 is associated with lower risk of non-Hodgkin's lymphoma (Lan et al., 2009) and higher risk of esophageal adenocarcinoma (Liu et al., 2010). Some cautions should be applied in interpreting conclusions from a single report of an association between a genetic variant and disease susceptibility, with greater weight placed upon associations replicated across multiple study cohorts (Xu et al., 2012; Zhang et al., 2013b; Yan et al., 2013). It should also be emphasized that due to linkage disequilibrium, a diseaseassociated SNP can tag multiple alleles. Thus, even robust associations between a genetic locus and a disease phenotype requires additional validation to link a specific gene product with a pathogenic SNP. Consequently, while multiple polymorphisms near the CASP9 locus associate with differential cancer risk, further study will need to clarify which, if any, of these variants cause pathogenic alterations in caspase-9 activity or expression.

\section{CASPASE-9 IN NEUROLOGIC PATHOLOGIES}

The most well-studied context of pathological caspase-9 activation is in neurodegenerative disease, where multiple studies have reported increased expression of both total and cl-caspase- 9 in apoptotic neurons, glial cells, serum and CSF (Table 2). Neurodegenerative disorders are characterized by progressive loss of neuronal function, and typically feature an increasing burden of neuronal cell death over the course of disease. Treatment strategies for neurodegenerative pathologies typically focus on supportive therapies, and interventions that modify the progression of neuronal loss are still mostly in experimental stages of development (Gan et al., 2018).

Kiechle et al. (Kiechle et al., 2002) reported increased expression of cl-caspase- 9 in postmortem brains from patients with Huntington's disease (HD), an inherited neurodegenerative disease caused by CAG repeat expansions in the huntingtin gene. HD features neuronal loss in the striatal part of the basal ganglia, leading to movement, cognitive and psychiatric disorders. Brain samples from patients with end-stage disease had greater expression of caspase-3 and D330 cl-caspase-9 in striatal neurons, suggesting activation of the apoptotic cascade. The study found that increasing cytosolic cytochrome $\mathrm{c}$ immunoreactivity in neurons was associated with increased striatal degeneration, indicating that activation of intrinsic 
apoptotic signaling contributes to neuronal death at end-stage disease. Increased caspase activity was also reported in cultured blood cells from HD patients (Squitieri et al., 2011), suggesting that CAG repeat expansions result in increased susceptibility to caspase activation. HD progression has also been associated with mitochondrial dysfunction (Yablonska et al., 2019), potentially implicating both apoptotic and mitochondrial functions of caspase-9 signaling in HD neurodegeneration. Expression of endogenous inhibitor of apoptosis proteins, IAP1 and XIAP, is markedly reduced in HD post-mortem human brain tissue, pointing to IAP-mediated regulation of caspase activity as a potential therapeutic target in HD (Goffredo et al., 2005).

Kawamoto et al. (Kawamoto et al., 2016) examined cl-caspase-9 expression in postmortem brain sections from donors with multiple system atrophy (MSA), a rare sporadic neurodegenerative disorder. The study found D330 cl-caspase-9 in oligodendrocytes and in neuronal and glial cytoplasmic inclusions, supporting involvement of both caspase-9 and caspase-3 in neurodegenerative pathology. Rodent and nonhuman primate models of multiple system atrophy (Lee et al., 2019; Marmion et al., 2021) offer experimental tools to investigate cell-specific consequences of caspase- 9 activation in neurons and glia and enable studies to test the therapeutic potential of caspase- 9 inhibitors as a neuroprotective strategy in MSA.

Increased caspase- 9 activity has also been implicated in Alzheimer's disease, the most common cause of dementia in older adults, whose neuronal pathology features progressive accumulation of amyloid plaques, neurofibrillary tangles, and synaptic loss. Rohn et al. (Rohn et al., 2002) reported autocleaved (D315) caspase-9 expression in neurons and neurofibrillary tangles in hippocampal sections from patients with Alzheimer's disease (AD), implicating caspase-9 activation and caspase- 3 mediated cleavage of tau in $\mathrm{AD}$ pathogenesis. More recently, Zhao et al. (Zhao et al., 2016) found progressively increasing levels of total caspase- 9 and other pro-apoptotic proteins in platelet rich plasma from patients with amnesic mild cognitive impairment (a loss of cognitive function that can progress to an $\mathrm{AD}$ diagnosis) and $\mathrm{AD}$ compared to subjects without cognitive deficits. The correlation between caspase-9 blood protein levels and cognitive impairment suggest systemic alterations in apoptosis regulation may be implicated in the progression of neurodegenerative disease. Both neurovascular pathologies and systemic abnormalities in innate immune system response have been implicated in $\mathrm{AD}$ pathogenesis (Fani Maleki and Rivest, 2019). Given the enormous complexity of $\mathrm{AD}$ neurodegeneration, it is not surprising that alterations in caspase- 9 signaling have been noted across multiple cell types in AD tissues. Cell-type specific inhibition strategies can help discriminate between different caspase- 9 signaling pathways and elucidate which caspase- 9 activities are potential therapeutic targets in AD.

Two studies reported increased expression of cleaved and total caspase-9 in amyotrophic lateral sclerosis (ALS), a neuromuscular disease driven by degeneration of motor neurons in the brain and spinal cord. Inoue et al. (Inoue et al., 2003) identified cl-caspase- 9 in spinal cord motor neurons and measured increased caspase activity by LEHD-cleavage in anterior horn lysates from patients with ALS. The study also showed that overexpression of XIAP in motor neurons (which inhibits caspases-9,-3,-7) attenuated disease progression in a SOD1 transgenic mouse model of ALS. More recently, Ilzecka et al. (Ilzecka, 2012) measured increased levels of total caspase-9 in serum samples from patients with diagnosed ALS. The study found that serum caspase- 9 correlated significantly with both duration and severity of ALS. These findings invite further investigation to explore how caspase- 9 activity is systemically dysregulated in ALS and to test if pharmacological approaches targeting caspase- 9 can replicate the therapeutic benefit of XIAP overexpression.

The association of increased caspase- 9 expression with neurodegeneration is not limited to chronic neurodegenerative diseases. Two studies reported increased levels of full-length and cleaved caspase-9 in CSF of patients with traumatic brain injury (TBI) (Darwish and Amiridze, 2010; Jiang et al., 2020). Although these studies do not indicate the cellular origin of CSF caspase-9, immunohistochemical localization data on caspase-7 (a downstream target of caspase-9) in surgical resections of injured brain tissue after severe TBI, suggests involvement of neuronal, glial, perivascular and hematopoietic caspase activation (Zhang et al., 2006). In a rat model of blunt ocular trauma, treatment with a highly selective caspase-9 inhibitor, Pen1-XBir3, reduces neuronal death and improves retinal function, supporting the role of caspase- 9 in mediating neuronal death in an acute trauma model (Blanch et al., 2014). Animal models of TBI can help evaluate the therapeutic potential of caspase- 9 inhibitors in treating neurovascular and neuroinflammatory sequelae of traumatic brain injury.

Neurodegenerative pathologies features upregulated caspase- 9 in neuronal and glial cells, as well as in patient CSF and blood serum samples. These studies indicate that caspase- 9 mediates common pathways of neuronal injury across multiple neurodegenerative pathologies, and suggest increasing caspase9 involvement in later stages of disease when neuronal death is prevalent. However, further study is needed to elucidate how different neurodegenerative etiologies induce caspase- 9 activation, to clarify the significance of caspase- 9 activity in non-neuronal cell types, and to determine whether targeting caspase- 9 activity can offer a therapeutic strategy for treating neurodegenerative disease. Given the multimodal role of caspase9 in regulating neuronal circuit organization, mitochondrial homeostasis, innate immune response, and neurovascular barrier disruption, it is highly likely that caspase-9 involvement in neurodegenerative pathologies is likewise heterogeneous.

\section{CASPASE-9 IN RETINAL NEUROPATHY}

Retinal cell death contributes to permanent vision loss in ophthalmic disease, and neuroprotective treatment strategies may translate to vision-saving treatments for retinal disorders such as photoreceptor degeneration, diabetic retinopathy, and glaucoma (Pardue and Allen, 2018). Several studies have implicated caspase- 9 in ocular pathologies, supporting caspase- 
TABLE 3 | Studies reporting increased level of caspase-9 in retinal disease.

\begin{tabular}{|c|c|c|c|c|c|c|}
\hline Disease (n) & Controls (n) & Casp9 Measured & Detection Method & Tissue Examined & $\begin{array}{c}\text { Pathological Casp9 } \\
\text { Localization }\end{array}$ & Ref. \\
\hline $\mathrm{RD}(4)$ & Normal (10) & Unspecified cl-casp9 & $\mathrm{IHC}$ & Retina (postmortem) & Photoreceptors & Hisatomi et al. (2008) \\
\hline RRD (33) & -- & D315 cl-casp9 & Immunoassay & Subretinal fluid & -- & Carpineto et al. (2016) \\
\hline T2D (10) & Normal (10) & Unspecified cl-casp9 & $\mathrm{IHC}$ & Retina (postmortem) & Ganglion cell layer & Oshitari et al. (2008) \\
\hline Glaucoma (10-38) & Normal (10-30) & Unspecified cl-casp9 & LC-MS/MS, Western blot, IHC & Retina (postmortem) & Ganglion cells & Yang et al. (2011) \\
\hline
\end{tabular}

$R D$, Retinal detachment; $R R D$, rhegmatogenous retinal detachment; T2D, Type 2 diabetes.

9 as a potential therapeutic in treatment of degenerative eye disease (Table 3).

Carpineto et al. (Carpineto et al., 2016) detected D315 cl-caspase9, and other apoptotic signaling proteins, in subretinal fluid from patients with rhegmatogenous retinal detachment (RRD). Rhegmatogenous detachments are caused by a hole or tear in the retina, which allows fluid to accumulate in the subretinal space, requiring emergency treatment by intraocular surgery. The study associated increased levels of cl-caspase- 9 with severity and duration of retinal detachment. Retinal detachment uncouples photoreceptors from choroidal circulation, resulting in hypoxic injury and neuronal death. Data on cellular localization of caspase-9 in human retinal detachments is limited to a study from Hisatomi et al. (Hisatomi et al., 2008), who showed colocalization of cl-caspase-9 with $\mathrm{TUNEL}^{+}$photoreceptors in four retinas from donors with retinal detachment. However, it is not clear if degenerating photoreceptors are the primary source of cleaved caspase- 9 in subretinal fluid from RRD. Intriguingly, it is endothelial caspase- 9 activity that regulates severity of retinal detachment and subsequent photoreceptor injury in mouse studies (Avrutsky et al., 2020). XIAP overexpression confers neuroprotection in rodent and feline injury models (Zadro-Lamoureux et al., 2009; Wassmer et al., 2017), and pharmacological inhibition of caspase- 9 by Pen1-XBir3 reduces severity of retinal detachment in mouse retinal vein occlusion (Avrutsky et al., 2020), supporting caspase-9 activity as a potential therapeutic target for retinal detachments. Pharmacological interventions aimed at reducing apoptotic signaling may confer therapeutic benefit in patients awaiting ocular surgery. Such an approach is being tested with an antiapoptotic Fas receptor antagonist (ONL1204), which recently entered clinical development as a complementary therapy for treating RRD (Krishnan et al., 2019). Therapies targeted at caspase-9 signaling may provide an alternative approach for inhibiting detachment-induced photoreceptor injury.

Caspase- 9 activation also occurs in retinal ganglion neurons in patients with type 2 diabetes (Oshitari et al., 2008) and in patients with glaucoma (Yang et al., 2011). To date, studies of caspase-9 in ocular disease have focused on photoreceptors and ganglion neurons, and unbiased profiling of caspase- 9 signaling may reveal a broader cellular signature of caspase- 9 involvement in ocular disease. Present studies support the pro-apoptotic role of caspase- 9 as a mediator of neuronal cell death in both cerebral and retinal pathologies, and future interventional studies in animal models of glaucoma and diabetic retinopathy can help discern the therapeutic potential of caspase- 9 inhibition for attenuating retinal pathologies.

\section{CASPASE-9 IN LUMBAR DISC DISEASE AND MYASTHENIC DISORDERS}

Musculoskeletal conditions are injuries and disorders that affect the body's bones, joints, and muscles. Caspase- 9 upregulation has been associated with the progression of myopathy in slowchannel syndrome (SCS, a myasthenic disorder caused by mutations in acetylcholine receptors) and in intervertebral disk degeneration in lumbar disc disease (LDD) (Table 4).

Vohra et al. (Vohra et al., 2004) reported activation of caspase-9 in neuromuscular junctions from four patients with SCS. Activation of caspase- 9 was detected in $15-57 \%$ of endplates, similar to the proportion of endplates with degenerating mitochondria or vacuoles, and vastly exceeding the number of neuromuscular junctions with nuclear degeneration. The findings suggest that caspase- 9 activation plays a prominent role in SCS degenerative processes. Selective caspase-9 inhibition decreases subsynaptic DNA damage, increases endplate area, and improves ultrastructural abnormalities in an SCS transgenic mouse model (Zhu et al., 2014). Currently, the principal treatment modalities for SCS are long-lived open-channel blockers of the acetylcholine receptor ion channel, but expanding the understanding of the mechanisms of neuromuscular transmission, maintenance, and repair may yield novel therapeutic strategies for SCS and related myasthenia disorders (Farmakidis et al., 2018).

A combination of genetic and histologic studies have identified an association between caspase- 9 and lumbar disc disease (LDD).

TABLE 4 | Studies reporting increased level of caspase-9 in lumbar and myasthenic disorders.

\begin{tabular}{lllllll}
\hline Disease (n) & Control (n) & Casp9 Measured & Detection Method & Tissue examined & \multicolumn{1}{c}{$\begin{array}{c}\text { Pathological Casp9 } \\
\text { Localization }\end{array}$} \\
\hline SCS (4) & Normal (4) & Unspecified cl-casp9 & IHC & Anconeus muscle (biopsy) & Neuromuscular junction \\
LDH (84) & -- & Total casp9 & IHC & Intervertebral disc (biopsy) & Cartilage, fibroblasts, inflammatory cells & Ozevren et al. (2020)
\end{tabular}

SCS, Slow-channel syndrome; LDH, lumbar disc herniation. 
TABLE 5 | Studies reporting altered levels of caspase-9 in autoimmune disease.

\begin{tabular}{|c|c|c|c|c|c|c|}
\hline Disease (n) & Controls (n) & Casp9 Measured & Detection Method & Tissue examined & $\begin{array}{c}\text { Pathological Casp9 } \\
\text { Localization }\end{array}$ & Ref. \\
\hline Sepsis (107) & $\begin{array}{l}\text { Normal (89) } \\
\text { SIRS (75) }\end{array}$ & Total casp9 & ELISA & Serum & -- & Miliaraki et al. (2021) \\
\hline $\begin{array}{l}\text { Immunodeficiency/ } \\
\text { Iymphoproliferation (2) }\end{array}$ & -- & $\begin{array}{l}\text { Caspase activity } \\
\text { Casp9 H237P }\end{array}$ & $\begin{array}{l}\text { LEHD cleavage } \\
\text { Genotyping }\end{array}$ & Blood & PBMC & Clemente et al. (2015) \\
\hline Behçet's disease (15) & Normal (9) & Total casp9 & $\| \mathrm{HC}$ & Aphthous lesion (biopsy) & Endothelial cells & Oztas et al. (2007) \\
\hline Behcet's disease (7) & Normal (7) & Caspase activity & LEHD cleavage & Blood & Neutrophils & Nazıroğlu et al. (2014) \\
\hline
\end{tabular}

SIRS, Traumatic Systemic Inflammatory Syndrome; PBMCs, Peripheral blood mononuclear cells.

Lumbar disk disease occurs when intervertebral disks degenerate, bulge from the bony area of the lower spine, and eventually herniate. The herniated disk can press on nerve roots in the lumbar spine, causing back pain, weakness or numbness. Treatment strategies for LDD depend on severity of disease, ranging from conservative pain management to surgical interventions that excise herniated lumbar segments, and restorative pharmacological treatments are still in early experimental stages of development (Wu et al., 2020).

Guo et al. (Guo et al., 2011b) examined CASP9 polymorphisms in patients with lower back pain and identified a significant association with the rs4645978 polymorphism in the CASP9 promoter region. This association has since been replicated in two other studies (Zhang et al., 2013a; Mu et al., 2013). Sun et al. (Sun et al., 2011) reported an additional association between the caspase-9 Q221R mutation (rs1052576) and lumbar disc disease, however both associations have so far only been tested in populations of Chinese ancestry.

Histologic evidence of caspase-9 involvement in LDD comes from a study by Ozevren et al. (Ozevren et al., 2020), who investigated the relationship between caspase- 9 expression in discectomy samples and MRI grading of lumbar disc herniation. Biochemical and histological analyses found that increasing inflammation, collagen fiber deterioration, apoptotic process, TNFa and caspase-9 expression were all associated with more severe disc grading based on lumbar spine MRI. Caspase- 9 was detected in degenerating cartilage cells, fibroblasts and extravasated inflammatory cells. Discectomy samples with disc protrusion (a more severe grade of disease) showed 2-fold higher levels of caspase activity, compared to samples with disc sequestration (an earlier stage of disc degeneration), suggesting that disc degeneration increases apoptotic processes. The study implicates caspase-9 in LDD progression, and may inform development of restorative treatments aimed at early inflammatory and degenerative disc changes. However, without further experimental evidence, it remains unclear whether caspase- 9 activity drives disc degeneration, or whether increased caspase- 9 activation is a downstream correlate of tissue injury.

\section{CASPASE-9 IN IMMUNE PATHOLOGIES}

Biochemical evidence links caspase-9 with immunodeficiency, sepsis, and Behcet's disease (Table 5). Sepsis is a devastating clinical condition characterized by dysregulated host response to infection, which can lead to multi-organ failure and death. Miliaraki et al. (Miliaraki et al., 2021) examined serum caspase levels in patients with sepsis. Serum caspase-9 was significantly related to levels of BIRC5 (inhibitor of caspase-9 activation), and achieved the best receiver operating characteristic curve (AUROC) for predicting mortality and for discriminating between septic patients and either traumatic systemic inflammatory response syndrome (SIRS) or healthy controls. Caspase- 9 regulates expression of type 1 interferons, and caspase- 9 deficiency is protective against viral lethality in mice (Rongvaux et al., 2014), supporting further studies into whether caspase- 9 inhibition may help improve survival in septic patients.

Increased caspase-9 expression has also been reported in Behcet's disease, a multisystem disorder of unknown etiology that is driven by endothelial inflammation. Oztaş et al. (Oztas et al., 2007) measured approximately 50\% increase in mean caspase-9-positive endothelial cell counts in oral biopsies of aphthous lesions from patients with Behcet's disease, compared to skin biopsies from healthy controls or patients with psoriasis. Higher levels of caspase activity were also measured in neutrophils isolated from Behcet's patients (approximately 60\% higher than control), along with other markers of apoptosis and oxidative stress (Nazıroğlu et al., 2014). Together these studies associate elevated caspase-9 activity with systemic inflammatory pathologies. While no animal models fully recapitulate the phenotype of Behcet's disease, several approaches enable relevant experimental study of autoimmune dysregulation (Charles et al., 2020). Since caspase- 9 can contribute to both apoptotic and nonapoptotic endothelial dysfunction, examining regulation of caspase- 9 activity in different vascular pathologies may give insight into endothelial physiology and vascular health. Likewise, given the association between caspase-9 loss-of-function mutations and immune system deficits (as described in Section 4) further study is warranted to clarify the consequences of altered caspase- 9 expression in patient leukocytes and to distinguish between apoptotic and nonapoptotic roles of caspase- 9 in immune disease.

\section{CASPASE-9 IN CARDIOVASCULAR PATHOLOGIES}

Cardiovascular disorders, including atherosclerosis and cardiomyopathies are the leading causes of mortality in the 
TABLE 6 | Studies reporting increased level of caspase-9 in cardiovascular pathologies.

\begin{tabular}{|c|c|c|c|c|c|c|}
\hline Disease (n) & Controls (n) & $\begin{array}{c}\text { Casp9 } \\
\text { Measured }\end{array}$ & Detection Method & Tissue Examined & $\begin{array}{l}\text { Pathological Casp9 } \\
\text { Localization }\end{array}$ & Ref. \\
\hline ICM (24) CR (15) & $\begin{array}{l}\text { Cardiac allograft } \\
\text { donors (5) }\end{array}$ & D315 cl-casp9 & Western blot & $\begin{array}{l}\text { Myocardium (heart } \\
\text { transplant) }\end{array}$ & -- & Tung et al. (2003) \\
\hline DCM (13) & $\begin{array}{l}\text { Aortic stenosis (12) } \\
\text { ICM (13) }\end{array}$ & D315 cl-casp9 & Immunoassay & Myocardium (biopsy) & -- & $\begin{array}{l}\text { Neidhardt et al. } \\
\text { (2019) }\end{array}$ \\
\hline DCM (36) & Donor hearts (10) & $\begin{array}{l}\text { D315 cl-casp9 } \\
\text { CASP9 mRNA }\end{array}$ & $\begin{array}{l}\text { Western blot, cDNA } \\
\text { array }\end{array}$ & Left ventricle (biopsy) & -- & $\begin{array}{l}\text { Aharinejad et al. } \\
\text { (2008) }\end{array}$ \\
\hline iDCM (22) & DCM (10) & Total casp9 & ELISA & $\begin{array}{l}\text { Serum, endomyocardium } \\
\text { (biopsy) }\end{array}$ & -- & $\begin{array}{l}\text { Bironaite et al. } \\
\text { (2015) }\end{array}$ \\
\hline $\begin{array}{l}\text { CP/Rep + } \\
\text { Diabetes (16) }\end{array}$ & Normal (8) & D330 cl-casp9 & Western blot & Right atrium (biopsy) & -- & Feng et al. (2013) \\
\hline Cardioplegia (30) & Preoperative samples & CASP9 mRNA & RT-PCR & Blood & -- & Elcik et al. (2021) \\
\hline $\begin{array}{l}\text { Atherosclerosis } \\
\text { (25) }\end{array}$ & -- & CASP9 mRNA & RT-PCR & Thoracic aorta (biopsy) & Fatty streak lesions & $\begin{array}{l}\text { Sobenin et al. } \\
\text { (2015) }\end{array}$ \\
\hline $\begin{array}{l}\text { Atherosclerosis } \\
\text { (12) }\end{array}$ & Normal (6) & D330 cl-casp9 & $\mathrm{IHC}$ & Aorta (biopsy) & $\begin{array}{l}\text { Endothelium, fibrous } \\
\text { plaques }\end{array}$ & $\begin{array}{l}\text { Niculescu et al. } \\
\text { (2004) }\end{array}$ \\
\hline
\end{tabular}

ICM, Ischemic cardiomyopathy; CR, chronic rejection; DCM, Dilated cardiomyopathy; iDCM, inflammatory dilated cardiomyopathy; CP/Rep, Cardioplegic arrest and reperfusion.

industrialized world (Arnett et al., 2019). Cardiovascular disease progression culminates in end-stage heart failure, requiring transplantation as the treatment modality of choice in eligible patients. There is an urgent need to develop therapies that can prevent heart failure, and evidence-based treatment algorithms to manage treatment of the disease (Crespo-Leiro et al., 2018).

Atherosclerosis is a disease of the arteries characterized by endothelial activation, inflammation and deposition of fibrous fatty deposits in the vessel walls. Increased expression and activation of caspase- 9 has been reported in two studies of atherosclerotic arteries (Table 6). Niculescu et al. (Niculescu et al., 2004) immunostained atherosclerotic human aorta samples, and detected D330 cl-caspase-9 in endothelial cells and in fibrous plaques. Parallel TUNEL staining experiments revealed prevalent cell death in these types of lesions. More recently, Sobenin et al. (Sobenin et al., 2015) measured 2-fold increased expression of CASP9 mRNA in atherosclerotic fatty streak (type II) lesions compared to unaffected intima, initial lesions, lipofibrous plaques or fibrous plaques from thoracic aorta biopsies. Additionally, the A28V/G mutation in caspase-9 has been associated with decreased risk of ischemic stroke (Lee et al., 2017), supporting a possible causative connection between caspase-9 and vascular disease. These studies provide a glimpse into mechanisms of both transcriptional and posttranslational caspase-9 regulation in vascular pathologies. Broad spectrum caspase inhibition reduces cell death in the arteries of rabbits fed a high-cholesterol diet and subjected to aortic balloon de-endothelialization (Sarai et al., 2007), providing supporting evidence that caspases contribute to vascular injury. However the specific role of caspase-9 in atherosclerotic vessels remains oblique, and further study of caspase- 9 signaling is warranted in animal models that can recapitulate the lipoprotein metabolism and chronic inflammatory features of atherosclerotic vessels. Dysregulation of innate immunity is a driver of cardiovascular disease (Saltiel and Olefsky, 2017), implying that both pro-apoptotic and immune-regulatory functions of caspase-9 may be involved. Further research may identify common caspase-9-mediated pathways in autoimmune dysfunction and cardiovascular disease.

Cardiac pathologies are associated with inflammation arising from innate immune system activation related to cardiac damage, creating a rich milieu of both inflammatory and apoptotic caspase signaling (Jaén et al., 2020). In mouse development, caspase-9 plays an essential nondeath role in muscle and cardiomyocyte differentiation and proliferation (Murray et al., 2008; Bulatovic et al., 2015), supporting both apoptotic and nonapoptotic pathways of potential caspase-9 involvement in heart disease. Biopsy and serum samples from several cardiac pathologies feature increased levels of total and cleaved caspase-9 (Table 6). Differential expression of caspase- 9 neoepitopes and downstream effector caspases in different forms of cardiomyopathy suggests that multiple caspase-9 signaling pathways are involved in these disorders.

Two studies identified increased expression of caspase- 9 in myocardial tissues following induction of cardioplegic arrest, a technique which induces cessation of cardiac function to minimize myocardial damage during open heart surgeries. Cardioplegic arrest and reperfusion (CR/Rep) renders the heart globally ischemic, and can trigger myocardial injury upon reperfusion. Feng et al. (Feng et al., 2013) showed increased D330 clcaspase-9 expression and increased TUNEL staining in atrium biopsies collected from diabetic patients after $\mathrm{CP} / \mathrm{Rep}$, compared to nondiabetic controls. Combined with the reported increase in caspase-9 activation in diabetic retinas (Oshitari et al., 2008), these results support a common association between diabetes, caspase-9 activation, and increased susceptibility to ischemic cell death across different organ systems. More recently, Elcik et al. (Elcik et al., 2021) showed greater CASP9 mRNA induction in blood samples from patients who underwent custodiol cardioplegia compared to blood cardioplegia. In combination with other autophagy, apoptosis and hypoxia markers, CASP9 expression was associated with hypoxic myocardial damage. However, it is not clear how myocardial injury would be mechanistically linked with the reported changes in blood mRNA measures. 
TABLE 7 | Summary of caspase-9 involvement in human degenerative pathologies.

\begin{tabular}{|c|c|c|c|c|}
\hline Disease & $\begin{array}{l}\text { Tissue localization of } \\
\text { pathologic Caspase-9 expression }\end{array}$ & $\begin{array}{l}\text { Fluid Samples with } \\
\text { Increased Caspase-9 }\end{array}$ & $\begin{array}{l}\text { Strength of } \\
\text { evidence }\end{array}$ & $\begin{array}{l}\text { Summary of evidence linking } \\
\text { caspase- } 9 \text { with human pathology }\end{array}$ \\
\hline \multicolumn{5}{|c|}{ Human pathologies associated with Caspase-9 loss of function } \\
\hline Immunodeficiency/lymphoproliferation & -- & -- & Strong & $\begin{array}{l}\text {-Functional human genetics } \\
\text {-Knockout mouse phenotype }\end{array}$ \\
\hline Neural tube defects & -- & -- & Strong & $\begin{array}{l}\text {-Functional human genetics } \\
\text {-Knockout mouse phenotype }\end{array}$ \\
\hline Pediatric brain tumors (Li-Fraumeni-like syndrome) & -- & -- & Strong & -Functional human genetics \\
\hline \multicolumn{5}{|c|}{ Human pathologies associated with increased Caspase- 9 activity or expression } \\
\hline Amyotrophic lateral sclerosis & Motor neurons & Serum & Moderate & $\begin{array}{l}\text {-Therapeutic effect in animal models } \\
\text { - Correlation with disease severity }\end{array}$ \\
\hline Retinal detachment & Photoreceptors & Subretinal fluid & Moderate & $\begin{array}{l}\text { - Therapeutic effect in animal models } \\
\text {-Correlation with disease severity }\end{array}$ \\
\hline Slow-Channel syndrome & Neuromuscular junctions & & Moderate & $\begin{array}{l}\text {-Therapeutic effect in animal models } \\
\text {-Increased signal in patient samples }\end{array}$ \\
\hline Alzheimer's disease & Neurons, neurofibrillary tangles & Platelet rich plasma & Weak & -Correlation with disease severity \\
\hline Atherosclerosis & Aorta & -- & Weak & -Increased signal in patient samples \\
\hline Behcet's disease & Endothelial cells, neutrophils & -- & Weak & -Increased signal in patient samples \\
\hline Cardiomyopathy & Myocardium & Serum & Weak & -Increased signal in patient samples \\
\hline Cardioplegia & Myocardium & Blood & Weak & -Increased signal in patient samples \\
\hline Chronic rejection of heart transplant & Myocardium & -- & Weak & -Correlation with disease severity \\
\hline Diabetic retinopathy & Retinal ganglion neurons & -- & Weak & -Increased signal in patient samples \\
\hline Glaucoma & Retinal ganglion neurons & -- & Weak & -Increased signal in patient samples \\
\hline Huntington's disease & Neurons, neuropil & CSF & Weak & -Correlation with disease severity \\
\hline Multiple system atrophy & Neurons, oligodendrocytes, glia & - & Weak & -Increased signal in patient samples \\
\hline Sepsis & -- & Serum & Weak & -Correlation with disease severity \\
\hline Traumatic brain injury & -- & CSF & Weak & -Correlation with disease severity \\
\hline Lumbar disc disease & Cartilage, fibroblasts, inflammatory cells & -- & Weak & $\begin{array}{l}\text {-Correlation with disease severity } \\
\text { - Genetic association studies }\end{array}$ \\
\hline
\end{tabular}

Summary of pathologies associated with either caspase-9 loss of function or upregulated caspase-9, and level of evidence implicating caspase-9 as a potential driver of disease pathology.

Tung et al. (Tung et al., 2003) examined the role of caspase- 9 signaling in myocardium and coronary arteries in explanted hearts from patients with ischemic cardiomyopathy (ICM) and patients with chronic rejection of heart transplant. TUNEL labeling of dying myocytes in both ICM and chronic rejection tissues correlated positively with levels of cl-caspase- 9 and clcaspase-3. Cleaved caspase- 9 also showed a strong negative correlation to the time of survival of the initial allograft for retransplanted patients. In contrast, a recent study (Neidhardt et al., 2019) examined myocardial biopsies from patients with ischemic cardiomyopathy, and did not detect increased expression of either cl-caspase-9, cl-caspase-3, or cl-caspase-8 compared to aortic stenosis controls. It remains to be clarified whether patient selection or choice of controls substantially influenced the apparent differences in cl-caspase- 9 detection in ICM.

Caspase-9 involvement has also been reported in nonischemic myocardial pathologies. Three studies have implicated caspase- 9 in dilated cardiomyopathy (DCM), a form of myocardial degeneration that causes weakening and enlargement of the heart. Aharinejad et al. (Aharinejad et al., 2008) reported increased levels of cleaved and total caspase- 9 in left ventricle samples from patients with DCM. A later study (Bironaite et al., 2015) surveyed caspase-9 expression in patients with inflammation-positive DCM and inflammation-negative DCM, and found higher levels of caspase- 9 compared to caspase- 8 or caspase-3, with differential expression in serum and endomyocardial biopsy samples. Most recently, Neidhardt et al. (Neidhardt et al., 2019) reported a 2-fold increase of D315 cl-caspase-9 in myocardial biopsies from patients with DCM and did not detect increased cl-caspase- 3 or cl-caspase- 8 expression. Together these studies show that specifically caspase-
9, but not caspases-3, or -8 are induced in DCM pathology. Selective upregulation of specific caspases in DCM provides a unique opportunity to understand differential signaling roles of these caspases in degenerative and inflammatory pathologies.

To date, studies of caspase- 9 involvement in heart disease have relied primarily on biochemical detection methods, and we still do not know the cellular localization of caspase- 9 in these pathologies, limiting our understanding of the signaling pathways regulating caspase-9 in cardiomyopathy. These reports remain agnostic regarding whether caspase signaling mediates cell death in DCM patients. On the other hand, CP/ Rep and chronic rejection of heart transplant clearly link caspase9 activation with cell death. Correlational studies indicate a close association between caspase- 9 expression and disease severity, however further interventional studies in animal models of DCM would be helpful to establish whether inhibiting caspase-9 may provide therapeutic benefit in these disorders.

\section{CONCLUSION}

Caspase-9 has multiple apoptotic and nonapoptotic cellular functions, which complicates interpretations of caspase-9 expression in disease tissues. While colocalization of caspase- 9 with dying neurons has been established in several neurodegenerative conditions, its nonapoptotic roles in immune regulation, endothelial function, mitochondrial homeostasis and neuronal circuit organization substantially expand the potential scope of caspase- 9 involvement in disease (Table 7). In particular, our mechanistic understanding of caspase-9 signaling in lumbar disc disease, cardiovascular disease, and Behcet's disease are limited to phenomenological 
observations. Studies can utilize inducible cell-specific knockout of caspase- 9 to dissect cellular signaling pathways in the context of animal disease models. Meanwhile, development and adoption of selective inhibitors in experimental models is essential to clarify which caspase signaling pathways are plausible therapeutic targets.

Human genetic evidence implicates caspase- 9 loss of function mutations with neural tube defects, pediatric tumors, and immunodeficiency/lymphoproliferation. These loss of function phenotypes help elucidate the diverse roles played by caspase- 9 in different tissues, but are not readily tractable for caspase-9targeted therapeutic interventions due to the inherent risks of induced cell death caused by caspase- 9 upregulation. Gene association studies suggest potential caspase- 9 involvement with multiple cancers, autoimmune disorders, and neurological disease. Clinicogenomic analysis of caspase- 9 activity and expression in patient tissues should help clarify IF putative pathogenic CASP9 SNPs are specifically associated with alterations in caspase-9 signaling. Furthermore, coding variants A28V/G (rs1052571) and Q221R (rs1052576) are still not characterized for how they may impact caspase-9 signaling, despite extensive associations of these mutants with multiple cancers and degenerative and inflammatory pathologies. Understanding the functional consequence of these mutations would provide key genetic evidence to determine if caspase- 9 is a disease-causing target in diseases associated with these variants.

Pathogenic expression and activation of caspase- 9 has been reported in neuronal, vascular, lumbar, myocardial and hematopoietic tissues. Interventional studies in animal models support caspase- 9 as a driver of disease pathology in ALS, retinal detachment, and SCS, suggesting that inhibiting caspase-9 activity can be a viable therapeutic strategy for these disorders. However, for the majority of human pathologies associated with upregulated caspase- 9 , the therapeutic potential of caspase- 9 inhibition strategies has not yet been tested. Exploring caspase signaling across different organ systems can help expand our

\section{REFERENCES}

Aharinejad, S., Andrukhova, O., Lucas, T., Zuckermann, A., Wieselthaler, G., Wolner, E., et al. (2008). Programmed Cell Death in Idiopathic Dilated Cardiomyopathy Is Mediated by Suppression of the Apoptosis Inhibitor Apollon. Ann. Thorac. Surg. 86, 109-114. doi:10.1016/j.athoracsur.2008.03.057 Akpan, N., Serrano-Saiz, E., Zacharia, B. E., Otten, M. L., Ducruet, A. F., Snipas, S. J., et al. (2011). Intranasal Delivery of Caspase-9 Inhibitor Reduces Caspase-6dependent Axon/Neuron Loss and Improves Neurological Function After Stroke. J. Neurosci. 31, 8894-8904. doi:10.1523/JNEUROSCI.0698-11.2011

Allan, L. A., and Clarke, P. R. (2009). Apoptosis and Autophagy: Regulation of Caspase- 9 by Phosphorylation. Febs J. 276, 6063-6073. doi:10.1111/j.17424658.2009.07330.x

An, H. K., Chung, K. M., Park, H., Hong, J., Gim, J. E., Choi, H., et al. (2019). CASP9 (Caspase 9) Is Essential for Autophagosome Maturation Through Regulation of Mitochondrial Homeostasis. Autophagy 16 (9), 1-20.

Andreoli, V., Trecroci, F., La Russa, A., Valentino, P., Condino, F., Latorre, V., et al. (2009). CASP-9: A Susceptibility Locus for Multiple Sclerosis in Italy. J. Neuroimmunol. 210, 100-103. doi:10.1016/j.jneuroim.2009.03.013

Arnett, D. K., Blumenthal, R. S., Albert, M. A., Buroker, A. B., Goldberger, Z. D., Hahn, E. J., et al. (2019). 2019 ACC/AHA Guideline on the Primary Prevention of Cardiovascular Disease: A Report of the American College of Cardiology/ understanding of degenerative diseases by examining cell-type specific dysfunction subsequent to caspase- 9 activation. Eye research is readily translatable to CNS disease due to the shared neurovascular architecture of brain and retinal tissues (London et al., 2013), and caspase-9 likely shares signaling pathways in CNS and retinal neurodegeneration. Meanwhile the nonapoptotic role of caspase- 9 in immune response may illuminate the pathogenic roles of caspases in cardiovascular, musculoskeletal, and neurodegenerative pathologies.

\section{AUTHOR CONTRIBUTIONS}

MA: Conception, literature search, and writing of the manuscript. CT: Literature search, interpretation and critical revision. All authors approved the final manuscript and agreed to be responsible for this review.

\section{FUNDING}

This work was supported by the National Institute of Neurological Disorders and Stroke, grants RO1 NS081333, R03 NS099920 to CT.

\section{ACKNOWLEDGMENTS}

We want to thank members of our team and especially James Belarde for help with editing the manuscript. Figures $\mathbf{1}$ and $\mathbf{2}$ was created with BioRender.com. The Genotype-Tissue Expression (GTEx) Project was supported by the Common Fund of the Office of the Director of the National Institutes of Health, and by NCI, NHGRI, NHLBI, NIDA, NIMH, and NINDS. The data used for the analyses described in this manuscript were obtained from: the GTEx Portal (https://www.gtexportal.org) on 03/6/2021.
American Heart Association Task Force on Clinical Practice Guidelines. Circulation 140, e596-e646. doi:10.1161/CIR.0000000000000678

Avrutsky, M. I., Ortiz, C. C., Johnson, K. V., Potenski, A. M., Chen, C. W., Lawson, J. M., et al. (2020). Endothelial Activation of Caspase-9 Promotes Neurovascular Injury in Retinal Vein Occlusion. Nat. Commun. 11, 3173. doi:10.1038/s41467-020-16902-5

Baechler, B. L., Bloemberg, D., and Quadrilatero, J. (2019). Mitophagy Regulates Mitochondrial Network Signaling, Oxidative Stress, and Apoptosis During Myoblast Differentiation. Autophagy 15, 1606-1619. doi:10.1080/ 15548627.2019.1591672

Bironaite, D., Daunoravicius, D., Bogomolovas, J., Cibiras, S., Vitkus, D., Zurauskas, E., et al. (2015). Molecular Mechanisms Behind Progressing Chronic Inflammatory Dilated Cardiomyopathy. BMC Cardiovasc. Disord. 15, 26. doi:10.1186/s12872-015-0017-1

Blanch, R. J., Ahmed, Z., Thompson, A. R., Akpan, N., Snead, D. R., Berry, M., et al. (2014). Caspase-9 Mediates Photoreceptor Death after Blunt Ocular Trauma. Invest. Ophthalmol. Vis. Sci. 55, 6350-6357. doi:10.1167/iovs.13-13708

Bratton, S. B., and Salvesen, G. S. (2010). Regulation of the Apaf-1-Caspase-9 Apoptosome. J. Cell Sci. 123, 3209-3214. doi:10.1242/jcs.073643

Bulatovic, I., Ibarra, C., Österholm, C., Wang, H., Beltrán-Rodríguez, A., VarasGodoy, M., et al. (2015). Sublethal Caspase Activation Promotes Generation of Cardiomyocytes from Embryonic Stem Cells. PLoS One 10, e0120176. doi:10.1371/journal.pone.0120176 
Carpineto, P., Aharrh-Gnama, A., Ciciarelli, V., Borrelli, E., Petti, F., Aloia, R., et al. (2016). Subretinal Fluid Levels of Signal-Transduction Proteins and Apoptosis Molecules in Macula-Off Retinal Detachment Undergoing Scleral Buckle Surgery. Invest. Ophthalmol. Vis. Sci. 57, 6895-6901. doi:10.1167/ iovs.16-20372

Charles, J., Castellino, F. J., and Ploplis, V. A. (2020). Past and Present Behçet's Disease Animal Models. Curr. Drug Targets 21, 1652-1663. doi:10.2174/ 1389450121666200719010425

Chee, J. L., Saidin, S., Lane, D. P., Leong, S. M., Noll, J. E., Neilsen, P. M., et al. (2013). Wild-type and Mutant P53 Mediate Cisplatin Resistance Through Interaction and Inhibition of Active Caspase-9. Cell Cycle 12, 278-288. doi:10.4161/cc.23054

Cingeetham, A., Vuree, S., Dunna, N. R., Gorre, M., Nanchari, S. R., Edathara, P. M., et al. (2014). Association of Caspase9 Promoter Polymorphisms with the Susceptibility of AML in South Indian Subjects. Tumour Biol. 35, 8813-8822. doi:10.1007/s13277-014-2096-5

Clemente, N., Boggio, E., Gigliotti, C. L., Orilieri, E., Cappellano, G., Toth, E., et al. (2015). A Mutation in Caspase-9 Decreases the Expression of BAFFR and ICOS in Patients with Immunodeficiency and Lymphoproliferation. Genes Immun. 16, 151-161. doi:10.1038/gene.2014.74

Costa, E. F. D., Lopes-Aguiar, L., Nogueira, G. S., Lima, T. R. P., Rinck-Junior, J. A., Lourenço, G. J., et al. (2019). CASP9 c.-1339A $>$ G and CASP3 c.-1191A>G Polymorphisms Alter Susceptibility and Clinical Aspects of Head and Neck Squamous Cell Carcinoma. Head Neck 41, 2665-2670. doi:10.1002/hed.25746

Cravo, M., Ferreira, P., Sousa, P., Moura-Santos, P., Velho, S., Tavares, L., et al. (2014). Clinical and Genetic Factors Predicting Response to Therapy in Patients with Crohn's Disease. United Eur. Gastroenterol J. 2, 47-56. doi:10.1177/ 2050640613519626

Crespo-Leiro, M. G., Metra, M., Lund, L. H., Milicic, D., Costanzo, M. R., Filippatos, G., et al. (2018). Advanced Heart Failure: A Position Statement of the Heart Failure Association of the European Society of Cardiology. Eur. J. Heart Fail. 20, 1505-1535. doi:10.1002/ejhf.1236

Darwish, R. S., and Amiridze, N. S. (2010). Detectable Levels of Cytochrome C and Activated Caspase- 9 in Cerebrospinal Fluid After Human Traumatic Brain Injury. Neurocrit. Care 12, 337-341. doi:10.1007/s12028-009-9328-3

Denault, J. B., Eckelman, B. P., Shin, H., Pop, C., and Salvesen, G. S. (2007). Caspase 3 Attenuates XIAP (X-Linked Inhibitor of Apoptosis Protein)-Mediated Inhibition of Caspase 9. Biochem. J. 405, 11-19. doi:10.1042/BJ20070288

Elcik, D., Tuncay, A., Sener, E. F., Taheri, S., Tahtasakal, R., Mehmetbeyoğlu, E., et al. (2021). Blood mRNA Expression Profiles of Autophagy, Apoptosis, and Hypoxia Markers on Blood Cardioplegia and Custodiol Cardioplegia Groups. Braz. J. Cardiovasc. Surg. [Epub ahead of print]. doi:10.21470/1678-9741-20200330

Fani Maleki, A., and Rivest, S. (2019). Innate Immune Cells: Monocytes, Monocyte-Derived Macrophages and Microglia as Therapeutic Targets for Alzheimer's Disease and Multiple Sclerosis. Front. Cel Neurosci. 13, 355. doi:10.3389/fncel.2019.00355

Farmakidis, C., Pasnoor, M., Barohn, R. J., and Dimachkie, M. M. (2018). Congenital Myasthenic Syndromes: A Clinical and Treatment Approach. Curr. Treat. Options. Neurol. 20, 36. doi:10.1007/s11940-018-0520-7

Feng, J., Liu, Y., Dobrilovic, N., Chu, L. M., Bianchi, C., Singh, A. K., et al. (2013). Altered Apoptosis-Related Signaling After Cardioplegic Arrest in Patients with Uncontrolled Type 2 Diabetes Mellitus. Circulation 128, S144-S151. doi:10.1161/CIRCULATIONAHA.112.000332

Ferreira, P., Cravo, M., Guerreiro, C. S., Tavares, L., Santos, P. M., and Brito, M. (2010). Fat Intake Interacts with Polymorphisms of Caspase9, FasLigand and PPARgamma Apoptotic Genes in Modulating Crohn's Disease Activity. Clin. Nutr. 29, 819-823. doi:10.1016/j.clnu.2010.06.008

Fogarty, C. E., and Bergmann, A. (2017). Killers Creating New Life: Caspases Drive Apoptosis-Induced Proliferation in Tissue Repair and Disease. Cell Death Differ. 24, 1390-1400. doi:10.1038/cdd.2017.47

Gan, L., Cookson, M. R., Petrucelli, L., and La Spada, A. R. (2018). Converging Pathways in Neurodegeneration, from Genetics to Mechanisms. Nat. Neurosci. 21, 1300-1309. doi:10.1038/s41593-018-0237-7

Goffredo, D., Rigamonti, D., Zuccato, C., Tartari, M., Valenza, M., and Cattaneo, E. (2005). Prevention of Cytosolic IAPs Degradation: A Potential Pharmacological Target in Huntington's Disease. Pharmacol. Res. 52, 140-150. doi:10.1016/ j.phrs.2005.01.006
Grossi, S., Fenini, G., Kockmann, T., Hennig, P., Di Filippo, M., and Beer, H. D. (2020). Inactivation of the Cytoprotective Major Vault Protein by Caspase-1 and -9 in Epithelial Cells During Apoptosis. J. Invest. Dermatol. 140, 1335-1345.e10. doi:10.1016/j.jid.2019.11.015

Gu, Z., Serradj, N., Ueno, M., Liang, M., Li, J., Baccei, M. L., et al. (2017). Skilled Movements Require Non-apoptotic Bax/Bak Pathway-Mediated Corticospinal Circuit Reorganization. Neuron 94, 626. doi:10.1016/j.neuron.2017.04.019

Gu, Z., Koppel, N., Kalamboglas, J., Alexandrou, G., Li, J., Craig, C., et al. (2020). Semaphorin-mediated Corticospinal Axon Elimination Depends on the Activity-Induced Bax/Bak-Caspase Pathway. J. Neurosci. 40, 5402. doi:10.1523/JNEUROSCI.3190-18.2020

Guo, C., Ahmad, T., Beckly, J., Cummings, J. R., Hancock, L., Geremia, A., et al. (2011a). Association of Caspase-9 and RUNX3 with Inflammatory Bowel Disease. Tissue Antigens 77, 23-29. doi:10.1111/j.1399-0039.2010.01569.x

Guo, T. M., Liu, M., Zhang, Y. G., Guo, W. T., and Wu, S. X. (2011b). Association Between Caspase-9 Promoter Region Polymorphisms and Discogenic Low Back Pain. Connect. Tissue Res. 52, 133-138. doi:10.3109/ 03008207.2010.487621

Hakem, R., Hakem, A., Duncan, G. S., Henderson, J. T., Woo, M., Soengas, M. S., et al. (1998). Differential Requirement for Caspase 9 in Apoptotic Pathways In Vivo. Cell 94, 339-352. doi:10.1016/s0092-8674(00)81477-4

Han, C., Liu, Z., Zhang, Y., Shen, A., Dong, C., Zhang, A., et al. (2020a). Tumor Cells Suppress Radiation-Induced Immunity by Hijacking Caspase 9 Signaling. Nat. Immunol. 21, 546-554. doi:10.1038/s41590-020-0641-5

Han, J., Hou, W., Goldstein, L. A., Stolz, D. B., Watkins, S. C., and Rabinowich, H. (2014). A Complex Between Atg7 and Caspase-9: A Novel Mechanism of Cross-Regulation Between Autophagy and Apoptosis. J. Biol. Chem. 289, 6485-6497. doi:10.1074/jbc.M113.536854

Han, J., Goldstein, L. A., Hou, W., Watkins, S. C., and Rabinowich, H. (2020b). Involvement of CASP9 (Caspase 9) in IGF2R/CI-MPR Endosomal Transport. Autophagy, 17, 1393. doi:10.1080/15548627.2020.1761742

Han, Y., Chen, Y. S., Liu, Z., Bodyak, N., Rigor, D., Bisping, E., et al. (2006). Overexpression of HAX-1 Protects Cardiac Myocytes From Apoptosis Through Caspase-9 Inhibition. Circ. Res. 99, 415-423. doi:10.1161/ 01.RES.0000237387.05259.a5

Harrison, S. A., Goodman, Z., Jabbar, A., Vemulapalli, R., Younes, Z. H., Freilich, B., et al. (2020). A Randomized, Placebo-Controlled Trial of Emricasan in Patients with NASH and F1-F3 Fibrosis. J. Hepatol. 72, 816-827. doi:10.1016/ j.jhep.2019.11.024

Hisatomi, T., Nakazawa, T., Noda, K., Almulki, L., Miyahara, S., Nakao, S., et al. (2008). HIV Protease Inhibitors Provide Neuroprotection Through Inhibition of Mitochondrial Apoptosis in Mice. J. Clin. Invest. 118, 2025-2038. doi:10.1172/JCI34267

Hlavaty, T., Pierik, M., Henckaerts, L., Ferrante, M., Joossens, S., Van Schuerbeek, N., et al. (2005). Polymorphisms in Apoptosis Genes Predict Response to Infliximab Therapy in Luminal and Fistulizing Crohn's Disease. Aliment. Pharmacol. Ther. 22, 613-626. doi:10.1111/j.1365-2036.2005.02635.x

Hosgood, H. D., 3rd, Baris, D., Zhang, Y., Zhu, Y., Zheng, T., Yeager, M., et al. (2008). Caspase Polymorphisms and Genetic Susceptibility to Multiple Myeloma. Hematol. Oncol. 26, 148-151. doi:10.1002/hon.852

Hu, S., Liu, Y., You, T., Heath, J., Xu, L., Zheng, X., et al. (2018). Vascular Semaphorin 7A Upregulation by Disturbed Flow Promotes Atherosclerosis Through Endothelial $\beta 1$ Integrin. Arterioscler Thromb. Vasc. Biol. 38, 335-343. doi:10.1161/ATVBAHA.117.310491

Hu, Z., Li, C., Chen, K., Wang, L. E., Sturgis, E. M., Spitz, M. R., et al. (2008). Single Nucleotide Polymorphisms in Selected Apoptotic Genes and BPDE-Induced Apoptotic Capacity in Apparently Normal Primary Lymphocytes: A GenotypePhenotype Correlation Analysis. J. Cancer Epidemiol. 2008, 147905. doi:10.1155/2008/147905

Huang, C. J., Wan, T. K., Fang, T. Y., and Wang, P. C. (2019). CASP9 Genotype Confers Gentamicin Susceptibility in Intratympanic Treatment of Intractable Vertigo Caused by Ménière's Disease. Acta Otolaryngol. 139, 336-339. doi:10.1080/00016489.2019.1575525

Ilzecka, J. (2012). Serum Caspase-9 Levels Are Increased in Patients with Amyotrophic Lateral Sclerosis. Neurol. Sci. 33, 825-829. doi:10.1007/s10072011-0837-4

Inoue, H., Tsukita, K., Iwasato, T., Suzuki, Y., Tomioka, M., Tateno, M., et al. (2003). The Crucial Role of Caspase-9 in the Disease Progression of a 
Transgenic ALS Mouse Model. Embo J. 22, 6665-6674. doi:10.1093/emboj/ cdg634

Jaén, R. I., Val-Blasco, A., Prieto, P., Gil-Fernández, M., Smani, T., LópezSendón, J. L., et al. (2020). Innate Immune Receptors, Key Actors in Cardiovascular Diseases. JACC: Basic Transl. Sci. 5, 735-749. doi:10.1016/ j.jacbts.2020.03.015

Jiang, W., Jin, P., Wei, W., and Jiang, W. (2020). Apoptosis in Cerebrospinal Fluid as Outcome Predictors in Severe Traumatic Brain Injury. Medicine (Baltimore) 99, e20922. doi:10.1097/md.0000000000020922

Julien, O., and Wells, J. A. (2017). Caspases and Their Substrates. Cell Death Differ. 24, 1380-1389. doi:10.1038/cdd.2017.44

Kawamoto, Y., Ayaki, T., Urushitani, M., Ito, H., and Takahashi, R. (2016). Activated Caspase-9 Immunoreactivity in Glial and Neuronal Cytoplasmic Inclusions in Multiple System Atrophy. Neurosci. Lett. 628, 207-212. doi:10.1016/j.neulet.2016.06.036

Kelly, J. L., Novak, A. J., Fredericksen, Z. S., Liebow, M., Ansell, S. M., Dogan, A., et al. (2010). Germline Variation in Apoptosis Pathway Genes and Risk of NonHodgkin's Lymphoma. Cancer Epidemiol. Biomarkers Prev. 19, 2847-2858. doi:10.1158/1055-9965.epi-10-0581

Kiechle, T., Dedeoglu, A., Kubilus, J., Kowall, N. W., Beal, M. F., Friedlander, R. M., et al. (2002). Cytochrome C and Caspase-9 Expression in Huntington's Disease. Neuromolecular Med. 1, 183-195. doi:10.1385/NMM:1:3:183

Krishnan, A., Kocab, A. J., Zacks, D. N., Marshak-Rothstein, A., and GregoryKsander, M. (2019). A Small Peptide Antagonist of the Fas Receptor Inhibits Neuroinflammation and Prevents Axon Degeneration and Retinal Ganglion Cell Death in an Inducible Mouse Model of Glaucoma. J. Neuroinflammation 16, 184. doi:10.1186/s12974-019-1576-3

Kuida, K., Haydar, T. F., Kuan, C. Y., Gu, Y., Taya, C., Karasuyama, H., et al. (1998). Reduced Apoptosis and Cytochrome C-Mediated Caspase Activation in Mice Lacking Caspase 9. Cell 94, 325-337. doi:10.1016/s0092-8674(00)81476-2

Lan, Q., Morton, L. M., Armstrong, B., Hartge, P., Menashe, I., Zheng, T., et al. (2009). Genetic Variation in Caspase Genes and Risk of Non-Hodgkin Lymphoma: A Pooled Analysis of 3 Population-Based Case-Control Studies. Blood 114, 264-267. doi:10.1182/blood-2009-01-198697

Lan, Q., Zheng, T., Chanock, S., Zhang, Y., Shen, M., Wang, S. S., et al. (2007). Genetic Variants in Caspase Genes and Susceptibility to Non-Hodgkin Lymphoma. Carcinogenesis 28, 823-827. doi:10.1093/carcin/bgl196

Lee, B. Y., Chon, J., Kim, H. S., Lee, J. H., Yun, D. H., Yoo, S. D., et al. (2017). Association Between a Polymorphism in CASP3 and CASP9 Genes and Ischemic Stroke. Ann. Rehabil. Med. 41, 197-203. doi:10.5535/ arm.2017.41.2.197

Lee, H. J., Ricarte, D., Ortiz, D., and Lee, S. J. (2019). Models of Multiple System Atrophy. Exp. Mol. Med. 51, 1-10. doi:10.1038/s12276-019-0346-8

Lee, S. Y., Choi, Y. Y., Choi, J. E., Kim, M. J., Kim, J. S., Jung, D. K., et al. (2010). Polymorphisms in the Caspase Genes and the Risk of Lung Cancer. J. Thorac. Oncol. 5, 1152-1158. doi:10.1097/JTO.0b013e3181e04543

Liamarkopoulos, E., Gazouli, M., Aravantinos, G., Tzanakis, N., Theodoropoulos, G., Rizos, S., et al. (2011). Caspase 8 and Caspase 9 Gene Polymorphisms and Susceptibility to Gastric Cancer. Gastric Cancer 14, 317-321. doi:10.1007/ s10120-011-0045-1

Lin, J., Lu, C., Stewart, D. J., Gu, J., Huang, M., Chang, D. W., et al. (2012). Systematic Evaluation of Apoptotic Pathway Gene Polymorphisms and Lung Cancer Risk. Carcinogenesis 33, 1699-1706. doi:10.1093/carcin/bgs192

Liu, C. Y., Wu, M. C., Chen, F., Ter-Minassian, M., Asomaning, K., Zhai, R., et al. (2010). A Large-Scale Genetic Association Study of Esophageal Adenocarcinoma Risk. Carcinogenesis 31, 1259-1263. doi:10.1093/carcin/ bgq092

Liu, X. Z., Zhang, Q., Jiang, Q., Bai, B. L., Du, X. J., Wang, F., et al. (2018). Genetic Screening and Functional Analysis of CASP9 Mutations in a Chinese Cohort with Neural Tube Defects. CNS Neurosci. Ther. 24, 394-403. doi:10.1111/ cns. 12797

London, A., Benhar, I., and Schwartz, M. (2013). The Retina as a Window to the Brain-From Eye Research to CNS Disorders. Nat. Rev. Neurol. 9, 44-53. doi:10.1038/nrneurol.2012.227

Lopez-Hernandez, F. J., Ortiz, M. A., Bayon, Y., and Piedrafita, F. J. (2004). Retinoid-related Molecules Require Caspase 9 for the Effective Release of Smac and the Rapid Induction of Apoptosis. Cel Death Differ 11, 154-164. doi:10.1038/sj.cdd.4401329
Lu, E. P., Mclellan, M., Ding, L., Fulton, R., Mardis, E. R., Wilson, R. K., et al. (2014). Caspase-9 Is Required for Normal Hematopoietic Development and Protection from Alkylator-Induced DNA Damage in Mice. Blood 124, 3887-3895. doi:10.1182/blood-2014-06-582551

Marmion, D. J., Rutkowski, A. A., Chatterjee, D., Hiller, B. M., Werner, M. H., Bezard, E., et al. (2021). Viral-based Rodent and Nonhuman Primate Models of Multiple System Atrophy: Fidelity to the Human Disease. Neurobiol. Dis. 148, 105184. doi:10.1016/j.nbd.2020.105184

Marusawa, H., Matsuzawa, S., Welsh, K., Zou, H., Armstrong, R., Tamm, I., et al. (2003). HBXIP Functions as a Cofactor of Survivin in Apoptosis Suppression. Embo J. 22, 2729-2740. doi:10.1093/emboj/cdg263

McCaughan, J. A., Mcknight, A. J., and Maxwell, A. P. (2014). Genetics of NewOnset Diabetes After Transplantation. J. Am. Soc. Nephrol. 25, 1037-1049. doi:10.1681/ASN.2013040383

McComb, S., Chan, P. K., Guinot, A., Hartmannsdottir, H., Jenni, S., Dobay, M. P., et al. (2019). Efficient Apoptosis Requires Feedback Amplification of Upstream Apoptotic Signals by Effector Caspase-3 or -7. Sci. Adv. 5, eaau9433. doi:10.1126/sciadv.aau9433

McDonnell, M. A., Abedin, M. J., Melendez, M., Platikanova, T. N., Ecklund, J. R., Ahmed, K., et al. (2008). Phosphorylation of Murine Caspase- 9 by the Protein Kinase Casein Kinase 2 Regulates its Cleavage by Caspase-8. J. Biol. Chem. 283, 20149-20158. doi:10.1074/jbc.M802846200

McStay, G. P., Salvesen, G. S., and Green, D. R. (2008). Overlapping Cleavage Motif Selectivity of Caspases: Implications for Analysis of Apoptotic Pathways. Cel Death Differ. 15, 322-331. doi:10.1038/sj.cdd.4402260

Miliaraki, M., Briassoulis, P., Ilia, S., Polonifi, A., Mantzourani, M., Briassouli, E., et al. (2021). Survivin and Caspases Serum Protein Levels and Survivin Variants mRNA Expression in Sepsis. Sci. Rep. 11, 1049. doi:10.1038/s41598-02078208-2

Molnár, T., Pallagi, P., Tél, B., Király, R., Csoma, E., Jenei, V., et al. (2021). Caspase9 Acts as a Regulator of Necroptotic Cell Death. Febs J. [Epub ahead of print]. doi:10.1111/febs. 15898

Morote-Garcia, J. C., Napiwotzky, D., Köhler, D., and Rosenberger, P. (2012). Endothelial Semaphorin 7A Promotes Neutrophil Migration during Hypoxia. Proc. Natl. Acad. Sci. U S A. 109, 14146-14151. doi:10.1073/ pnas. 1202165109

Mu, J., Ge, W., Zuo, X., Chen, Y., and Huang, C. (2013). Analysis of Association between IL-1 $\beta$, CASP-9, and GDF5 Variants and Low-Back Pain in Chinese Male Soldiers. Spi 19, 243-247. doi:10.3171/2013.4.spine12782

Murray, T. V., Mcmahon, J. M., Howley, B. A., Stanley, A., Ritter, T., Mohr, A., et al. (2008). A Non-apoptotic Role for Caspase-9 in Muscle Differentiation. J. Cel Sci. 121, 3786-3793. doi:10.1242/jcs.024547

Muskens, I. S., De Smith, A. J., Zhang, C., Hansen, H. M., Morimoto, L., Metayer, C., et al. (2020). Germline Cancer Predisposition Variants and Pediatric Glioma: A Population-Based Study in California. Neuro Oncol. 22, 864-874. doi:10.1093/neuonc/noaa014

Nakanishi, K., Maruyama, M., Shibata, T., and Morishima, N. (2001). Identification of a Caspase-9 Substrate and Detection of its Cleavage in Programmed Cell Death During Mouse Development. J. Biol. Chem. 276, 41237-41244. doi:10.1074/jbc.M105648200

Nazıroğlu, M., Sahin, M., Ciğ, B., Aykur, M., Erturan, I., and Ugan, Y. (2014). Hypericum perforatum Modulates Apoptosis and Calcium Mobilization Through Voltage-Gated and TRPM2 Calcium Channels in Neutrophil of Patients with Behcet's Disease. J. Membr. Biol. 247, 253-262. doi:10.1007/ s00232-014-9630-7

Neidhardt, S., Garbade, J., Emrich, F., Klaeske, K., Borger, M. A., Lehmann, S., et al. (2019). Ischemic Cardiomyopathy Affects the Thioredoxin System in the Human Myocardium. J. Card. Fail. 25, 204-212. doi:10.1016/ j.cardfail.2019.01.017

Niculescu, F., Niculescu, T., and Rus, H. (2004). C5b-9 Terminal Complement Complex Assembly on Apoptotic Cells in Human Arterial Wall with Atherosclerosis. Exp. Mol. Pathol. 76, 17-23. doi:10.1016/j.yexmp.2003.10.002

Nishimura, T., Xu, H., Iwasaki, M., Karigane, D., Saavedra, B., Takahashi, Y., et al. (2019). Sufficiency for Inducible Caspase-9 Safety Switch in Human Pluripotent Stem Cells and Disease Cells. Gene Ther. 27, 525-534. doi:10.1038/s41434-0200179-z

Ohsawa, S., Hamada, S., Kuida, K., Yoshida, H., Igaki, T., and Miura, M. (2010). Maturation of the Olfactory Sensory Neurons by Apaf-1/caspase-9-Mediated 
Caspase Activity. Proc. Natl. Acad. Sci. U S A. 107, 13366-13371. doi:10.1073/ pnas. 0910488107

Olsson, M., and Zhivotovsky, B. (2011). Caspases and Cancer. Cel Death Differ. 18, 1441-1449. doi:10.1038/cdd.2011.30

Oshitari, T., Yamamoto, S., Hata, N., and Roy, S. (2008). Mitochondria- and Caspase-dependent Cell Death Pathway Involved in Neuronal Degeneration in Diabetic Retinopathy. Br. J. Ophthalmol. 92, 552-556. doi:10.1136/ bjo.2007.132308

Ozdogan, S., Kafadar, A., Yilmaz, S. G., Timirci-Kahraman, O., Gormus, U., and Isbir, T. (2017). Role of Caspase-9 Gene Ex5+32 G>A (Rs1052576) Variant in Susceptibility to Primary Brain Tumors. Anticancer Res. 37, 4997-5000. doi:10.21873/anticanres.11912

Ozevren, H., Cetin, A., Baloglu, M., and Deveci, E. (2020). Evaluation of the Association Between Biochemical and Immunohistochemical Score of Caspase9 and TNFa, and the Grading of Lumbar Disc Herniation. Br. J. Neurosurg. 1-5. doi:10.1080/02688697.2020.1817314

Oztaş, P., Lortlar, N., Polat, M., Alli, N., Omeroğlu, S., and Basman, A. (2007). Caspase-9 Expression Is Increased in Endothelial Cells of Active Behçet's Disease Patients. Int. J. Dermatol. 46, 172-176. doi:10.1111/j.13654632.2007.03209.x

Pardue, M. T., and Allen, R. S. (2018). Neuroprotective Strategies for Retinal Disease. Prog. Retin. Eye Res. 65, 50-76. doi:10.1016/j.preteyeres.2018.02.002

Pereira, N. A., and Song, Z. (2008). Some Commonly Used Caspase Substrates and Inhibitors Lack the Specificity Required to Monitor Individual Caspase Activity. Biochem. Biophys. Res. Commun. 377, 873-877. doi:10.1016/j.bbrc.2008.10.101

Rohn, T. T., Rissman, R. A., Davis, M. C., Kim, Y. E., Cotman, C. W., and Head, E. (2002). Caspase-9 Activation and Caspase Cleavage of Tau in the Alzheimer's Disease Brain. Neurobiol. Dis. 11, 341-354. doi:10.1006/nbdi.2002.0549

Ronellenfitsch, M. W., Oh, J. E., Satomi, K., Sumi, K., Harter, P. N., Steinbach, J. P., et al. (2018). CASP9 Germline Mutation in a Family with Multiple Brain Tumors. Brain Pathol. 28, 94-102. doi:10.1111/bpa.12471

Rongvaux, A., Jackson, R., Harman, C. C., Li, T., West, A. P., De Zoete, M. R., et al. (2014). Apoptotic Caspases Prevent the Induction of Type I Interferons by Mitochondrial DNA. Cell 159, 1563-1577. doi:10.1016/j.cell.2014.11.037

Saltiel, A. R., and Olefsky, J. M. (2017). Inflammatory Mechanisms Linking Obesity and Metabolic Disease. J. Clin. Invest. 127, 1-4. doi:10.1172/JCI92035

Sarai, M., Hartung, D., Petrov, A., Zhou, J., Narula, N., Hofstra, L., et al. (2007). Broad and Specific Caspase Inhibitor-Induced Acute Repression of Apoptosis in Atherosclerotic Lesions Evaluated by Radiolabeled Annexin A5 Imaging. J. Am. Coll. Cardiol. 50, 2305-2312. doi:10.1016/j.jacc.2007.08.044

Serrano, B. P., Szydlo, H. S., Alfandari, D., and Hardy, J. A. (2017). Active SiteAdjacent Phosphorylation at Tyr-397 by C-Abl Kinase Inactivates Caspase-9. J. Biol. Chem. 292, 21352-21365. doi:10.1074/jbc.M117.811976

Shalini, S., Dorstyn, L., Dawar, S., and Kumar, S. (2015). Old, New and Emerging Functions of Caspases. Cel Death Differ. 22, 526-539. doi:10.1038/cdd.2014.216

Shultz, J. C., and Chalfant, C. E. (2011). Caspase 9b: A New Target for Therapy in Non-small-cell Lung Cancer. Expert Rev. Anticancer Ther. 11, 499-502. doi:10.1586/era.11.23

Sobenin, I. A., Bobryshev, Y. V., Korobov, G. A., Borodachev, E. N., Postnov, A. Y., and Orekhov, A. N. (2015). Quantitative Analysis of the Expression of Caspase 3 and Caspase 9 in Different Types of Atherosclerotic Lesions in the Human Aorta. Exp. Mol. Pathol. 99, 1-6. doi:10.1016/j.yexmp.2015.05.004

Spellicy, C. J., Norris, J., Bend, R., Bupp, C., Mester, P., Reynolds, T., et al. (2018). Key Apoptotic Genes APAF1 and CASP9 Implicated in Recurrent FolateResistant Neural Tube Defects. Eur. J. Hum. Genet. 26, 420-427. doi:10.1038/ s41431-017-0025-y

Squitieri, F., Maglione, V., Orobello, S., and Fornai, F. (2011). Genotype-, Aging-dependent Abnormal Caspase Activity in Huntington Disease Blood Cells. J. Neural Transm. (Vienna) 118, 1599-1607. doi:10.1007/s00702-0110646-1

Srinivasula, S. M., Ahmad, M., Guo, Y., Zhan, Y., Lazebnik, Y., Fernandes-Alnemri, T., et al. (1999). Identification of an Endogenous Dominant-Negative Short Isoform of Caspase-9 that Can Regulate Apoptosis. Cancer Res. 59, 999-1002. https://cancerres.aacrjournals.org/content/59/5/999.article-info

Sun, Z. M., Ling, M., Huo, Y., Chang, Y., Li, Y., Qin, H., et al. (2011). Caspase 9 Gene Polymorphism and Susceptibility to Lumbar Disc Disease in the Han Population in Northern China. Connect. Tissue Res. 52, 198-202. doi:10.3109/ 03008207.2010.510914
Tamaki, H., Harashima, N., Hiraki, M., Arichi, N., Nishimura, N., Shiina, H., et al. (2014). Bcl-2 Family Inhibition Sensitizes Human Prostate Cancer Cells to Docetaxel and Promotes Unexpected Apoptosis under Caspase-9 Inhibition. Oncotarget 5, 11399-11412. doi:10.18632/oncotarget.2550

Theodoropoulos, G. E., Gazouli, M., Vaiopoulou, A., Leandrou, M., Nikouli, S., Vassou, E., et al. (2011). Polymorphisms of Caspase 8 and Caspase 9 Gene and Colorectal Cancer Susceptibility and Prognosis. Int. J. Colorectal Dis. 26, 1113-1118. doi:10.1007/s00384-011-1217-5

Theodoropoulos, G. E., Michalopoulos, N. V., Panoussopoulos, S. G., Taka, S., and Gazouli, M. (2010). Effects of Caspase-9 and Survivin Gene Polymorphisms in Pancreatic Cancer Risk and Tumor Characteristics. Pancreas 39, 976-980. doi:10.1097/MPA.0b013e3181d705d4

Theodoropoulos, G. E., Michalopoulos, N. V., Pantou, M. P., Kontogianni, P., Gazouli, M., Karantanos, T., et al. (2012). Caspase 9 Promoter Polymorphisms Confer Increased Susceptibility to Breast Cancer. Cancer Genet. 205, 508-512. doi:10.1016/j.cancergen.2012.08.001

Török, N. J., Higuchi, H., Bronk, S., and Gores, G. J. (2002). Nitric Oxide Inhibits Apoptosis Downstream of Cytochrome C Release by Nitrosylating Caspase 9. Cancer Res. 62, 1648-1653. https://cancerres.aacrjournals.org/content/62/6/ 1648.long

Tung, T. C., Cui, G., Oshima, K., Laks, H., and Sen, L. (2003). Balanced Expression of Mitochondrial Apoptosis Regulatory Proteins Correlates with Long-Term Survival of Cardiac Allografts. Am. J. Physiol. Heart Circ. Physiol. 285, H2832-H2841. doi:10.1152/ajpheart.00054.2003

Vohra, B. P., Groshong, J. S., Maselli, R. A., Verity, M. A., Wollmann, R. L., and Gomez, C. M. (2004). Focal Caspase Activation Underlies the Endplate Myopathy in Slow-Channel Syndrome. Ann. Neurol. 55, 347-352. doi:10.1002/ana.10823

Vu, N. T., Park, M. A., Shultz, M. D., Bulut, G. B., Ladd, A. C., and Chalfant, C. E. (2016). Caspase-9b Interacts Directly with cIAP1 to Drive AgonistIndependent Activation of NF- $\mathrm{KB}$ and Lung Tumorigenesis. Cancer Res. 76, 2977-2989. doi:10.1158/0008-5472.CAN-15-2512

Wang, S. H., Martin, S. M., Harris, P. S., and Knudson, C. M. (2011). Caspase Inhibition Blocks Cell Death and Enhances Mitophagy but Fails to Promote T-Cell Lymphoma. PLoS One 6, e19786. doi:10.1371/journal.pone.0019786

Wassmer, S. J., Leonard, B. C., Coupland, S. G., Baker, A. N., Hamilton, J., Hauswirth, W. W., et al. (2017). Overexpression of the X-Linked Inhibitor of Apoptosis Protects Against Retinal Degeneration in a Feline Model of Retinal Detachment. Hum. Gene Ther. 28, 482-492. doi:10.1089/hum.2016.161

Wong, C. K., Chen, Z., So, K. L., Li, D., and Li, P. (2007). Polycomb Group Protein RING1B Is a Direct Substrate of Caspases-3 and -9. Biochim. Biophys. Acta 1773, 844-852. doi:10.1016/j.bbamcr.2007.02.005

Wu, C., Hong, S. G., Winkler, T., Spencer, D. M., Jares, A., Ichwan, B., et al. (2014). Development of an Inducible Caspase-9 Safety Switch for Pluripotent Stem Cell-Based Therapies. Mol. Ther. Methods Clin. Dev. 1, 14053. doi:10.1038/ mtm.2014.53

Wu, P. H., Kim, H. S., and Jang, I. T. (2020). Intervertebral Disc Diseases PART 2: A Review of the Current Diagnostic and Treatment Strategies for Intervertebral Disc Disease. Int. J. Mol. Sci. 21, 2135. doi:10.3390/ijms21062135

Xu, W., Jiang, S., Xu, Y., Chen, B., Li, Y., Zong, F., et al. (2012). A Meta-Analysis of Caspase 9 Polymorphisms in Promoter and Exon Sequence on Cancer Susceptibility. PLoS One 7, e37443. doi:10.1371/journal.pone.0037443

Yablonska, S., Ganesan, V., Ferrando, L. M., Kim, J., Pyzel, A., Baranova, O. V., et al. (2019). Mutant Huntingtin Disrupts Mitochondrial Proteostasis by Interacting with TIM23. Proc. Natl. Acad. Sci. U S A. 116, 16593-16602. doi:10.1073/pnas.1904101116

Yan, J., Ma, C., Cheng, J., Li, Z., and Liu, C. (2015). HAX-1 Inhibits Apoptosis in Prostate Cancer through the Suppression of Caspase-9 Activation. Oncol. Rep. 34, 2776-2781. doi:10.3892/or.2015.4202

Yan, S., Li, Y. Z., Zhu, X. W., Liu, C. L., Wang, P., and Liu, Y. L. (2013). Role of the CASP-9 Ex5+32 G>A Polymorphism in Susceptibility to Cancer: A MetaAnalysis. Exp. Ther. Med. 5, 175-180. doi:10.3892/etm.2012.756

Yang, X., Luo, C., Cai, J., Powell, D. W., Yu, D., Kuehn, M. H., et al. (2011). Neurodegenerative and Inflammatory Pathway Components Linked to TNFa/TNFR1 Signaling in the Glaucomatous Human Retina. Invest. Ophthalmol. Vis. Sci. 52, 8442-8454. doi:10.1167/iovs.11-8152

Yoo, S. S., Choi, J. E., Lee, W. K., Choi, Y. Y., Kam, S., Kim, M. J., et al. (2009). Polymorphisms in the CASPASE Genes and Survival in Patients with Early- 
Stage Non-small-cell Lung Cancer. J. Clin. Oncol. 27, 5823-5829. doi:10.1200/ JCO.2009.23.1738

Zadro-Lamoureux, L. A., Zacks, D. N., Baker, A. N., Zheng, Q. D., Hauswirth, W. W., and Tsilfidis, C. (2009). XIAP Effects on Retinal Detachment-Induced Photoreceptor Apoptosis [corrected]. Invest. Ophthalmol. Vis. Sci. 50, 1448-1453. doi:10.1167/iovs.08-2855

Zhang, D., Zhao, N., Ma, B., Wang, Y., Zhang, G., Yan, X., et al. (2016). Procaspase-9 Induces its Cleavage by Transnitrosylating XIAP via the Thioredoxin System during Cerebral Ischemia-Reperfusion in Rats. Sci. Rep. 6, 24203. doi:10.1038/srep24203

Zhang, S., Xiao, Q., Shi, Z., Yu, G., Ma, X.-P., Chen, H., et al. (2017). Caspase Polymorphisms and Prognosis of Hepatocellular Carcinoma. PLoS One 12, e0176802. doi:10.1371/journal.pone.0176802

Zhang, X., Alber, S., Watkins, S. C., Kochanek, P. M., Marion, D. W., Graham, S. H., et al. (2006). Proteolysis Consistent with Activation of Caspase-7 after Severe Traumatic Brain Injury in Humans. J. Neurotrauma 23, 1583-1590. doi:10.1089/neu.2006.23.1583

Zhang, Y. G., Zhang, F., Sun, Z., Guo, W., Liu, J., Liu, M., et al. (2013a). A Controlled Case Study of the Relationship Between Environmental Risk Factors and Apoptotic Gene Polymorphism and Lumbar Disc Herniation. Am. J. Pathol. 182, 56-63. doi:10.1016/j.ajpath.2012.09.013

Zhang, Z. Y., Xuan, Y., Jin, X. Y., Tian, X., and Wu, R. (2013b). CASP-9 Gene Functional Polymorphisms and Cancer Risk: A Large-Scale Association Study Plus MetaAnalysis. Genet. Mol. Res. 12, 3070-3078. doi:10.4238/2013.February.28.22
Zhao, S., Zhao, J., Zhang, T., and Guo, C. (2016). Increased Apoptosis in the Platelets of Patients with Alzheimer's Disease and Amnestic Mild Cognitive Impairment. Clin. Neurol. Neurosurg. 143, 46-50. doi:10.1016/ j.clineuro.2016.02.015

Zhou, X., Zeng, W., Li, H., Chen, H., Wei, G., Yang, X., et al. (2018). Rare Mutations in Apoptosis Related Genes APAF1, CASP9, and CASP3 Contribute to Human Neural Tube Defects. Cell Death Dis 9, 43. doi:10.1038/s41419-017-0096-2

Zhu, H., Pytel, P., and Gomez, C. M. (2014). Selective Inhibition of Caspases in Skeletal Muscle Reverses the Apoptotic Synaptic Degeneration in Slow-Channel Myasthenic Syndrome. Hum. Mol. Genet. 23, 69-77. doi:10.1093/hmg/ddt397

Conflict of Interest: CT is listed as an inventor on patent applications US20200164026, US20190142915, and MA and CT are listed as inventors on a patent application WO/2020/223212 by the Trustees of Columbia University in the City Of New York.

Copyright (c) 2021 Avrutsky and Troy. This is an open-access article distributed under the terms of the Creative Commons Attribution License (CC BY). The use, distribution or reproduction in other forums is permitted, provided the original author(s) and the copyright owner(s) are credited and that the original publication in this journal is cited, in accordance with accepted academic practice. No use, distribution or reproduction is permitted which does not comply with these terms. 